\title{
Majority Choice of an Income-Targeted Educational Voucher ${ }^{\dagger}$
}

\author{
By Dennis Epple, Richard Romano, and Sinan SarpÇA*
}

A model of majority choice of voucher characteristics with quantitative counterpart explains observed income eligibility requirements for educational vouchers. Households differ by income and preference for religious schooling. They elect a policy maker who chooses public school expenditure, a voucher, a maximum income for voucher eligibility, and a tax to finance public expenditure. Equilibrium has a voucher below per student public expenditure, an eligibility threshold near 300 percent of the poverty level, and a majority in public school though with substantial voucher usage, all properties typical of US voucher programs. Disallowing a voucher leads to higher per student public expenditure (JEL D72, H44, H71, I21, I22, I28).

number of educational voucher programs are currently operating in the United States, and a strong movement for introducing new and expanding existing programs persists. As summarized in tables 1 and 2 in Epple, Romano, and Urquiola (2017-henceforth, ERU), of the 14 currently operating programs, 13 are "income targeted," meaning eligibility for a voucher requires household income to be below a threshold. ${ }^{1}$ Another common feature of the programs is that the voucher level is below the expenditure per student in public schools (ERU). The majority of students continue to attend public schools in all cases. This paper develops a positive model of majority policy choice that can explain these features of voucher programs.

The logic underlying the analysis is straightforward. Income targeting combined with a voucher below per student public expenditure implies fiscal gains to public school students, as some students take up the voucher and exit public schools. The income targeting prevents subsidizing relatively high-income households that would attend private school without a voucher. A voucher below public expenditure is obviously necessary for public school students to realize fiscal gains as some

\footnotetext{
*Epple: Tepper School of Business, Carnegie Mellon University, Pittsburgh, PA 15213 (email: epple@cmu. edu); Romano: Department of Economics, University of Florida, Gainesville, FL 32611 (email: romanor@ufl. edu); Sarpça: Koc University, Sariyer 34450, Istanbul, Turkey (email: ssarpca@ku.edu.tr). The authors thank two anonymous referees for their comments, but retain responsibility for any errors.

Go to https://doi.org/10.1257/mic.20160141 to visit the article page for additional materials and author disclosure statement(s) or to comment in the online discussion forum.

${ }^{1}$ The Douglas County program reported in ERU Table 1 is not operating pending court approval. The income threshold for eligibility in the 13 operating programs ranges from 150 percent of the federally determined poverty level to 300 percent, with the latter threshold the most common. The Pennsylvania program has a $\$ 75,000$ household income threshold and requires assignment to an underperforming public school. Some of the other programs also provide a voucher to students assigned to a public school designated as failing. Programs targeted to disabled students are not included in the ERU analysis.
} 
students take a voucher and exit public schools. With public students in a majority, a program with such features has strong political support.

While the logic is simple and has been an element of some other analyses of vouchers discussed below, the challenge is to provide an analysis with endogenous public choice of the amount of the voucher, the income threshold for eligibility, expenditure per student in public schools, and the tax needed to finance public expenditures. While the policy vector can be reduced by one variable using the government balanced budget condition, the public choice problem remains three dimensional. With an unrestricted policy vector, majority choice equilibrium will generally fail to exist (Plott 1967). We resolve the existence problem using Besley and Coate's (1997) representative democracy model. The central idea is that voters elect a decision maker who can be anticipated to choose their preferred policy. Feasible policies are then restricted, which resolves the majority choice existence problem over a significant parameter space including empirically relevant cases.

We show that with realistic parameter restrictions equilibrium has a majority attending public school and an income-targeted voucher of magnitude below per student public expenditure. Calibrated to parameters matching the Milwaukee school district, which has the longest lived voucher program in the United States, the model predicts quite well the empirical levels of the voucher, the income threshold for eligibility, per student public expenditure, and private school attendance. The income threshold to qualify for the voucher is chosen in equilibrium so that high-income students that would attend private school without a voucher do not qualify to receive one. The latter set of students is joined in private schools by the wealthiest segment of those that qualify for a voucher, including students with strong religious preferences who use that voucher at religious schools.

The political equilibrium pits candidates that prefer a relatively high tax rate, public school expenditure, and voucher against candidates with the opposite preference. The poorest students who are in public school and students in private schools who do not qualify for a voucher prefer a candidate that would chose a lower tax rate policy. They are opposed by the relatively higher income students in public schools. Students in private schools that receive a voucher might in theory split in their preference, with some preferring a higher voucher and attendant higher tax rate while others prefer a lower voucher and lower tax rate. In our quantitative analysis we find, however, that all students that receive a voucher support candidates that prefer a lower tax even though such candidates would decrease the voucher. The coalition preferring a candidate that would set a higher tax rate, public school expenditure, and voucher must be balanced by those preferring the opposite in political equilibrium.

The quantitative analysis and findings bear emphasis. The political problem studied is complex, with four policy instruments and households that differ continuously by income (and hence policy preference) and dichotomously in preference for religious schooling. We are able to confirm majority choice equilibrium of a candidate that chooses a policy vector that conforms nicely to its empirical counterpart. To confirm equilibrium, we must characterize the policy preference of every individual should that individual choose to become a candidate. Thus, for example, we characterize the differences between policy preferences of 
religious and nonreligious candidates. Religious candidates have stronger preference to attend private schools that support their beliefs. In our main quantitative analysis any strongly religious individual would, if elected, choose a policy with a high enough voucher such that all strongly religious types (and others) would attend private school.

We also compare equilibrium with a voucher allowed to equilibrium when a voucher is prohibited. We find higher per student expenditure in public schools if a voucher is not allowed. Allowing a voucher induces an equilibrium with about twice as many students in private schools. The weakened support for taxation to finance education changes the political equilibrium. The voucher then "drains money from public schools," a mantra of voucher critics, though the logic is different than specious rhetoric that ignores cost savings in public schools.

We show majority preference for the targeted voucher regime over disallowing a voucher, provided equilibrium exists in both regimes. However, equilibrium allowing a targeted voucher can fail to exist as the proportion of religious households increases. As this proportion increases, the support for high-voucher candidates increases. When the proportion of religious households becomes sufficiently high, a proposal for a high-voucher defeats the proposal of the most popular alternative candidate-who proposes a policy under which a majority attend public school. The high-voucher proposal itself is, however, defeated by alternative proposals. Indeed, majority voting equilibrium then no longer exists. Remarkably, the "Top Cycle Set" is comprised of the entire set; there is a sequence of pairwise votes such that every candidate would emerge as the final winner. Under such circumstances, if a voucher-authorization vote precedes the vote over voucher characteristics, voters may conclude that it is prudent to deny authorization of a voucher program. This may account for the relatively low success rate of voucher programs at the authorization stage.

The paper unfolds as follows. Section I discusses related literature. Section II describes the baseline model, which has no religious preferences, along with some preliminary results. Section IIIA presents the main properties of equilibrium assuming existence. Section IIIB provides sufficient conditions for existence of equilibrium. Section IIIC introduces households with strong religious preferences, thus strong preferences for sending their children to private religious schools. Section IV develops the main quantitative analysis, with Section IVD revisiting the existence issue. Section V concludes. Much of the technical analysis is in appendices.

\section{Literature Review}

This paper builds on research on majority choice of voucher policy and related research on majority choice of public school tax and spending policy. Epple and Romano (2014) apply the representative democracy model to public choice of a universal voucher, which the present paper builds on..$^{2}$ Targeted vouchers and

\footnotetext{
${ }^{2}$ Earlier theoretical papers important to the development of the literature on public choice of vouchers are Ireland (1990), Rangazas (1995), and Hoyt and Lee (1998). These do not consider targeted vouchers. Epple and Romano (2014) discuss these important contributions in some detail.
} 
religious preferences are not considered. A few public choice papers consider targeted vouchers. Chen and West (2000) take as the status quo the majority choice equilibrium with public provision, where households can alternatively send their child to private school, but with no voucher. They examine whether a majority would prefer to switch to a universal voucher regime or to a regime with an income-targeted voucher having exogenous qualification threshold. Households first vote on switching to one of the voucher regimes, and then vote over the tax rate to finance vouchers and expenditure on public schools, with the requirement that the voucher equals per student expenditure in public schools under both voucher regimes. They make the point that the targeted voucher requires less public expenditure than the universal voucher because those that would select the private sector with no voucher continue to get no voucher in the targeted regime. Stronger collective preference for the targeted voucher then arises. The most important differences in the analysis here are the endogenous income threshold with the targeted voucher and that the voucher can be below public expenditure, the latter obviously crucial to explaining this empirical regularity. ${ }^{3}$ With Chen and West as his point of departure, Piolatto (2010) shows that the collective preference for a targeted voucher is increased if the cost of education provision in the public sector has diseconomies. As qualifying students switch into private schools, expenditure per student in public schools can be increased without increasing taxes and a Pareto improvement might result. As in Chen and West (2000), the amount of the voucher and the income threshold for qualification are exogenous. Finally, Bearse, Glomm, and Ravikumar (2000, 2003) examine a targeted voucher with endogenous characteristics, but with no public sector alternative. The voucher is specified to decrease linearly with household income until it reaches zero, with intercept and slope that are endogenous. Majority choice of an income tax occurs first, followed by majority choice of the slope term in the voucher specification with the intercept determined by government budget balance. It is shown in simulations that the voucher regime as described is frequently majority-preferred to the standard no-voucher regime with public provision but where students can alternatively choose private schools. Relative to the present paper, the most important difference is that a regime with vouchers and public provision is not considered. Our contribution is to provide an analysis with all characteristics endogenous that has the elements of the empirically relevant cases, and to show that the model can approximate empirical values.

\section{The Baseline Model and Preliminary Results}

We refer to the decision makers in the economy as "households" or "voters." Households differ only by income in the baseline model for simplicity.

\footnotetext{
${ }^{3}$ The model here also differs with respect to the timing. As described, Chen and West examine whether there would be a switch to a voucher regime with sequential voting over the regime switch followed by voting over the tax rate (with public expenditure equal to the voucher, these determined by budget balance and household choices). We ask whether an elected decision maker would enact a voucher with income targeting, while also determining the tax rate and public expenditure (subject to budget balance and household choices). Note that an elected decision maker could choose a universal voucher or no voucher, so that the character of the overall policy regime is endogenous. As noted, we also show that a constitutional amendment prohibiting a voucher would not be majority supported, provided equilibrium exists with the voucher allowed.
} 
A household has an endowed income $y$, a child in school, and utility function $U(x, q)$, where $x$ is numeraire consumption and $q$ is the quality of education. Educational quality is measured by per student expenditure in the student's school. The function $U$ is increasing, twice differentiable, and quasi-concave in $(x, q)$, and satisfies the standard Inada conditions. Ordinary demand for educational quality is normal. The population of households has continuous distribution on income $F(y)$, with density $f(y)$, positive on $\left[y_{\min }, y_{\max }\right] \subset[0, \infty)$. Normalize the population to one and denote mean income $Y$.

Households will choose to send their child to a public or private school. Let $g$ denote expenditure per student in the public sector, which is the same for every student attending a public school. Public finance is by a proportional income tax denoted $t$. Utility of household $y$ if their child attends a public school is then $U^{P}=U(y(1-t), g)$. Relevant to household preferences over $(t, g)$, we make the following assumption.

$$
\text { ASSUMPTION 1: }\left.\quad \frac{d t}{d g}\right|_{U^{P}=\text { const. }}=\frac{U_{q} / U_{x}}{y} \text { increases with } y .
$$

The single-crossing assumption means that the marginal willingness to bear a tax increase for higher $g$ increases with income; indifference curves drawn in the $(g, t)$ plane steepen as income rises. This implies that, among those that choose public schools, higher income voters support higher educational expenditure despite their higher tax price. Empirical evidence supports this assumption. ${ }^{4}$

To characterize utility if private school is attended, we must describe policy more fully. A policy vector is $\mathbf{p}=\left(t, v, g, y_{m}\right)$, where $v \geq 0$ denotes the voucher and $y_{m} \in\left[y_{\min }, y_{\max }\right]$ denotes the maximum income that is eligible to receive a voucher. This subsumes the case of a universal voucher, with everyone eligible, which has $y_{m}=y_{\max }$. We impose the following constitutional constraint on policies.

ASSUMPTION 2: $v \leq g$ if $y_{m}<y_{\max }$.

The idea is that every household has access to maximum public expenditure. If a voucher is offered with restricted eligibility, then it cannot provide more public schooling expenditure than available to ineligible households.

Private schooling is competitively provided with constant returns to scale. Thus, changes in a school's budget that are proportional to changes in the number of students in the school maintains quality. An implication is that "small" private schools can specialize to the desired expenditure of every household without adverse cost effects. ${ }^{5}$ Policy requires that all of $v>0$ is spent on education for those that

\footnotetext{
${ }^{4}$ Early empirical evidence is discussed in Epple and Romano (1996a). Epple and Sieg (1999) and Brunner and Ross (2010) provide alternative evidence supporting such an assumption. An Appendix to Epple and Romano (1996a) shows that Assumption 1 will be satisfied if the income elasticity of demand for educational quality is higher than the absolute value of the price elasticity of demand, provided the expenditure share on education is not too large. This theoretical characterization of the assumption derives from Kenny (1978).

${ }^{5}$ The constant returns to scale assumption is for simplicity. Introducing scale economies in schooling would likely reduce demand for private schools, but we avoid this complication.
} 
take a voucher and thus attend private school. A household that sends its child to private school obtains utility:

$$
U^{R}(z)=\max _{s \geq 0} U(y(1-t)-s, z+s), \quad \text { where } z=\left\{\begin{array}{ll}
v & \text { if } y \leq y_{m} \\
0 & \text { if } y>y_{m}
\end{array},\right.
$$

and $s$ is supplemental expenditure above the voucher. ${ }^{6}$ Denote the solution to the latter optimization $s^{*}(t, z, y)$.

Taking the policy vector as given, households choose a schooling alternative that maximizes utility, so utility is given by $\max \left[U^{P}, U^{R}\right]$. For given $(t, z, g)$ with $g>z$, a threshold income value $y_{T}(t, z, g)>0$ satisfying $U^{P}=U^{R}$ exists, such that households with public supplement $z$ (i.e., $v$ or 0 ) and income $y \geq(<) y_{T}$ will choose private (public) education. ${ }^{7}$ To break ties, we assume indifferent households choose private education without loss of generality. Simple comparative static properties are

$$
\frac{\partial y_{T}}{\partial t}>0 ; \quad \frac{\partial y_{T}}{\partial g}>0 ; \quad \text { and } \quad \frac{\partial y_{T}}{\partial z}<0
$$

The income of a household indifferent to public or private schooling rises if the tax increases or if the quality of public education rises. Increasing the voucher for private education has the opposite effect on voucher-eligible households. Assuming $v \in(0, g)$, note that $y_{T}(t, v, g)<y_{T}(t, 0, g)$, i.e., access to a voucher implies a wider income range of households attend private school. If $g=v$, then specify that $y_{T}=0$, consistent with the fact that no household would prefer the public alternative.

While we must consider all policy possibilities to find equilibrium, our focus will be on cases that have students in both public and private schools. We also assume the following for any $y_{m}$.

ASSUMPTION 3: For policy vectors with $g>v \geq 0$ : $(i) y_{\min }$ is sufficiently low so that the poorest income segment consumes public education; and (ii) $y_{\max }$ is sufficiently high that the richest income segment consumes private education even if ineligible for a voucher.

With the restriction $g>v$ in Assumption 3, the standard Inada condition on the utility function implies sufficiently poor households would not supplement a voucher, and so would necessarily prefer public education. Hence, Assumption 3(i) is that sufficiently poor households exist in the economy. If $y_{\max }$ exceeds $y_{T}(t, 0, g)$, then households with income in the range $\left[y_{T}(t, 0, g), y_{\max }\right]$ choose private education even without a voucher, and thus a fortiori with a voucher. Thus, Assumption 3 provides sufficient conditions such that both a public and private

\footnotetext{
${ }^{6}$ All of the current US voucher policies (for nondisabled students), with the exception of the policy in New Orleans, allow higher tuition than the amount of the voucher, some programs restricting this for the lowest income households. See ERU.

${ }^{7}$ This is straightforward to confirm and "well-known," so we omit proof. See Rangazas (1995).
} 


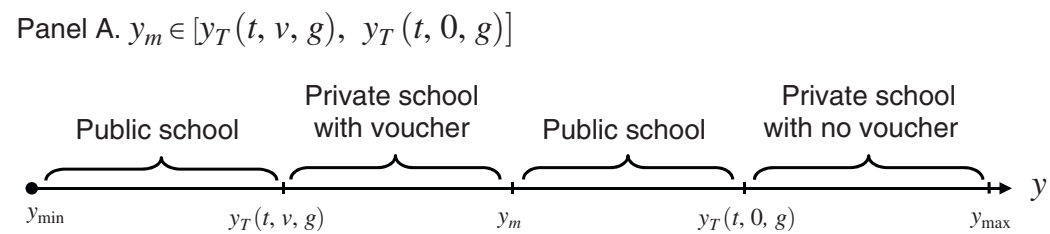

Panel B. $y_{m}>y_{T}(t, 0, g)$

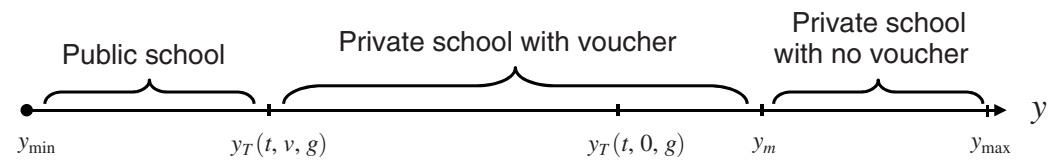

Panel C. $y_{m}<y_{T}(t, v, g)$

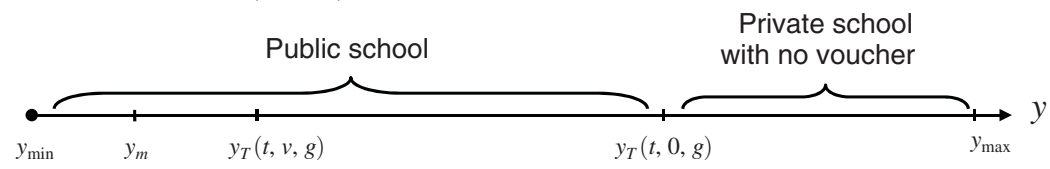

Figure 1. SCHOOL TyPe AND USE OF Voucher

sector will arise provided $g>v$. If $g=v$, then any eligible households are at least as well off with a voucher. We will show, however, that $g>v$ arises in equilibria of interest.

Lemma 1 describes the consumption pattern when $g>v$, summarized in the panels of Figure 1.

LEMMA 1: Assume $g>v \geq 0$. (i) If $y_{m} \in\left[y_{T}(t, v, g), y_{T}(t, 0, g)\right]$, then: households $\left[y_{T}(t, v, g), y_{m}\right]$ choose private education and get a voucher; households $\left(y_{m}, y_{T}(t, 0, g)\right)$ and $\left[y_{\min }, y_{T}(t, v, g)\right)$ choose public education; and households $\left[y_{T}(t, 0, g), y_{\max }\right]$ choose private education and do not get a voucher. (ii) If $y_{m}>y_{T}(t, 0, g)$, then: households $\left[y_{T}(t, v, g), y_{m}\right]$ choose private education and get a voucher; households $\left[y_{\min }, y_{T}(t, v, g)\right)$ choose public education; and households $\left[y_{m}, y_{\max }\right]$ choose private education and get no voucher (if there are any, i.e., if $\left.y_{m}<y_{\max }\right)$. (iii) If $y_{m}<y_{T}(t, v, g)$, then only households $\left[y_{T}(t, 0, g), y_{\max }\right]$ choose private education and no one gets a voucher.

Using the definitions of $y_{m}$ and $y_{T}(\cdot)$, the proof of Lemma 1 is trivial and omitted.

For cases with $g>v>0$, using Lemma 1, vouchers are used in equilibrium if $y_{m} \geq y_{T}(t, v, g)$. Then the government balanced budget condition is

(2A) $\quad v \int_{y_{T}(t, v, g)}^{y_{m}} f(y) d y+g F\left(y_{T}(t, v, g)\right)+g \int_{\min \left[y_{m}, y_{T}(t, 0, g)\right]}^{y_{T}\left(t, 0, y^{2}\right.} f(y) d y=t Y$. 
Departing from the condition of Lemma 1, if $v=g>0$, then the government budget constraint is

$$
g F\left(\max \left[y_{T}(t, 0, g), y_{m}\right]\right)=t Y .
$$

In the latter case, anyone who is eligible for the voucher uses it, and public expenditure on anyone who either can use the voucher or who cannot but chooses public school is the same. In any case, where no voucher is used in equilibrium $\left(v=0\right.$ or $\left.y_{m}<y_{T}(t, v, g)\right)$, then the government budget constraint is just

$$
g F\left(y_{T}(t, 0, g)\right)=t Y .
$$

Note that (2C) subsumes the case of $t=v=g=0$, where there is no public provision of any form. We must consider the latter case, since this policy is preferred by rich households as shown below.

Public choice of the policy vector is modeled using a version of Besley and Coate's (1997) representative democracy model. Our model has the technical difference that we assume a continuum of voters, while Besley and Coate (1997) assume a discrete distribution of voter types. The central assumption in Besley and Coate (1997) is that voters elect a policy maker correctly anticipating implementation of the policy maker's preferred policy. In addition to the latter, assume the following.

ASSUMPTION 4: Any voter can become a candidate at 0 cost. ${ }^{8}$

ASSUMPTION 5: If no candidate enters the race or if a positive measure of votes fails to materialize, then a relatively lousy policy $\mathbf{p}^{0}$ is implemented, which is worse for everyone than a positive measure of policies that some candidates would choose if elected. ${ }^{9}$

ASSUMPTION 6: Voting is costless and voters maximize their utility in Nash equilibrium, but never choose weakly dominated voting strategies.

ASSUMPTION 7: Assuming entry into the election, a candidate receiving a plurality of votes is elected, with equal probability tie breaking if multiple candidates tie for the win.

Equilibrium has rational expectations with the following sequence of choices. First, households simultaneously decide whether to become candidates. If no one enters, the lousy policy is implemented. Otherwise, a candidate is elected as described, whom we refer to as the superintendent. The superintendent then implements his preferred policy vector, which must be consistent with the next stage. Last, households optimize, choosing the public or private alternative, the latter with optimal supplement,

\footnotetext{
${ }^{8}$ Besley and Coate (1997) focus on cases with positive entry cost, though consider cases with vanishingly small entry cost.

${ }^{9}$ With no one in leadership, public policy is not as well managed as when some candidates are elected.
} 
and the government budget balances. When households optimize, they take as given the balanced budget policy vector, this consistent with the continuum of households and their implied inability to unilaterally affect the policy outcome. ${ }^{10}$

We examine cases that have a Condorcet winner among the preferred policies of households, which holds in our main analysis below. Let $\mathbf{p}^{*}(y)=\left(t^{*}(y), v^{*}(y), g^{*}(y), y_{m}^{*}(y)\right)$ denote a preferred policy vector of household $y$. Some cases of multiple preferred policies for household $y$ arise. A household that prefers to provide no voucher, could, with the same consequences, "provide" a voucher, but set $y_{m}$ low enough that no one would select the voucher. Of course, this multiplicity does not matter to any results. We encounter one other potential case of multiplicity. ${ }^{11}$ It has the superintendent indifferent among sets of households eligible for a voucher because $v=g$, with then no fiscal effects of varying the eligibility threshold over an income range. Here we assume the following.

ASSUMPTION 8 (Benevolence): A superintendent that is indifferent across values of $y_{m}$ chooses $y_{m}$ to maximize the set eligible for the voucher, implying a Pareto Improvement. With the latter restriction, the policy chosen by any elected superintendent is effectively unique.

An optimal policy for voter $y$ satisfies

$$
\max _{t \geq 0, v \geq 0, g \geq 0, y_{m} \in\left[y_{\min }, y_{\max }\right]}\left[\max \left\{U^{P}, U^{R}\right\}\right]
$$

subject to (2); all household's individual optimization; Assumption 2; and Assumption 8.

Let $\mathbf{P}^{*}=\left\{\mathbf{p}^{*}(y) \in \mathbb{R}_{+}^{4} \mid f(y)>0\right\}$ denote the set of preferred policy vectors. Given the continuum of types, a Condorcet winner is a policy $\mathbf{p}^{w} \in \mathbf{P}^{*}$ that is weakly preferred by at least one-half the measure of all voters $y$ over all alternative policies $\mathbf{p}^{*} \in \mathbf{P}^{*}$. Given existence of a $\mathbf{p}^{w}$, let $y^{w}$ denote a voter that prefers $\mathbf{p}^{w}$; i.e., $\mathbf{p}^{w}=\mathbf{p}^{*}\left(y^{w}\right)$.

Lemma 2 is an adaptation of Besley and Coate's Corollary 1 to our problem with a continuum of voters.

LEMMA 2 (Besley and Coate): Assuming a Condorcet winner $\mathbf{p}^{w}$ : (i) a single candidate equilibrium with candidate $y^{w}$ exists, with that candidate elected; and (ii) a single candidate equilibrium must have a $y^{w}$ elected.

The formal proof closely follows Besley and Coate, though we provide a proof in the online Appendix for convenience. Intuitively, entry by just a $y^{w}$ will lead to his election, to avoid the lousy alternative if no one is elected. No other candidate enters, since they would be defeated. Entry by just a household with alternative

\footnotetext{
${ }^{10}$ It is equivalent to require that the superintendent sets any three of the $\left(t, v, g, y_{m}\right)$ policy vector, with the other determined in the last stage under rational expectations. These are equivalent because households are "atomistic" policy takers.

${ }^{11}$ See the Proof of Proposition 1a in the Appendix.
} 
policy preference would not be an equilibrium, since entry by a $y^{w}$ leads to the latter's election.

Motivated by Lemma 2, we focus on equilibria with a policy vector that is a Condorcet winner among preferred policies. We show such equilibria exists over a significant parameter space in our quantitative analysis below (though not always) and discuss existence theoretically in Section IIIB. While existence holds under Lemma 2, uniqueness of political equilibrium is not implied, as Lemma 2 does not rule out multiple candidate equilibria. The online Appendix provides a modified two-party version of the model that also has uniqueness with the Condorcet winner the policy outcome.

A few elements of the model warrant further discussion. We have assumed school quality is determined solely by expenditure. Assuming quality increases with expenditure is reasonable, though empirical verification has been controversial. ${ }^{12}$ For simplicity, we have abstracted from peer effects in schools, though again their relevance is a contentious empirical issue. ${ }^{13}$ Equating school quality to expenditure, also abstracts from "horizontal" school differentiation. However, a form of horizontal differentiation arises in our analysis when we introduce religious preferences. In the full model with religious preferences, private school may be attractive to households because quality can be increased with higher expenditure and religious instruction can be provided for those who value it. ${ }^{14}$

\section{Properties of Equilibrium}

\section{A. Elements of Equilibrium with a Public and Private Sector}

In this subsection, we describe the central theoretical properties of equilibrium assuming existence of an equilibrium with both an active private and public sector. By "active," we mean that there are students attending both private and public schools rather than just having the option to do so. ${ }^{15}$ Section IIIB examines existence, including describing how we confirm existence in interesting cases. We now

\footnotetext{
${ }^{12}$ See Jackson, Johnson, and Persico (2016) for summary of the empirical literature and evidence that quality increases with expenditure.

${ }^{13}$ Introducing peer effects that have educational quality increase with average income of classmates is an interesting topic for future research, which would raise some modelling issues; e.g., whether peer characteristics are priced in private schools. Epple and Romano $(1998,2008)$ develop a model with vouchers that have private schools price peer effects, while Nechyba $(1999,2000,2003)$ develops a model with uniform within-school pricing of vouchers. See Epple and Romano (2011) for a survey of the literature on peer effects in education.

${ }^{14}$ Another simplifying assumption is that public expenditure on schooling is financed by an income tax, while schooling expenditure in the United States is financed by a combination of taxes, local, state, and federal, with significant proportion coming from property taxation. Local property taxation has been a declining source of public school funding, accounting for about 29 percent of school finance in 2014. The percentages of funding coming from federal, state, and local sources in 2014 were 8.6, 46.7, and 44.7. (Values are computed using Tables SS1400AD1 and SS1400A04, 2014 Annual Survey of School System Finances, US Census Bureau, https://www.census.gov/.) To consider property taxation, a housing market would need to be introduced. In as much as housing expenditures are proportional to income, as consistent with empirical evidence, using an income tax is reasonable in our model. Also, to the extent that state and federal funding is independent of local funding policies, our focus on local policy choice is also defensible.

${ }^{15}$ An equilibrium possibility, detailed below, has $v=g$ but with no students choosing the public alternative while having the option to do so.
} 
continue to assume no religious element to the model, allowing a clearer initial analysis. Proposition 1 collects key results.

\section{PROPOSITION 1:}

a. If equilibrium has active public and private sectors, then the elected superintendent chooses public school.

b. In any allocation (equilibrium or otherwise) with public school expenditure equal to $g$, all households that choose public school prefer the values of $v$ and $y_{m}$ that minimize $t$ subject to $(2 \mathrm{~A})$ for the given $g$.

c. Assume equilibrium has the superintendent choose public school and let $\left(g^{*}, t^{*}\right)$ denote the superintendent's choice of $(g, t)$. Then:

(i) a positive voucher $v^{*} \in\left(0, g^{*}\right)$ is chosen;

(ii) [Targeting] it is targeted with $y_{m}^{*}=y_{T}\left(t^{*}, 0, g^{*}\right)$;

(iii) [Balanced Voting Coalitions] the superintendent's income $y^{w}$ satisfies

$$
\int_{y^{w}}^{y_{T}\left(t^{*}, v^{*} g^{*}\right)} f(y) d y+\int_{\mathbf{Y}^{+}} f(y) d y=0.5
$$

where $\mathbf{Y}^{+}$is the income set of households (perhaps empty) that obtain a voucher and prefer election of a marginally higher income candidate, along with those that attend public school in the first integral. The remaining households are poorer households in public school with $y<y^{w}$ that all prefer a marginally lower income candidate and households in private school with or without a voucher that share this preference.

Proof is provided in the Appendix. Here we provide intuition. Consider Proposition 1a. A superintendent that prefers private education has a tax disincentive to set $g>v$ to support public education. Moreover, by setting $g=v$ and closing those households out of the voucher that would then choose public school implies no gains to the superintendent and would fail to satisfy the Benevolence Assumption 8. Thus, a superintendent that would prefer private education chooses $g=v>0$ and does not restrict access to the voucher or chooses $v=g=t=0$. Either choice effectively shut downs the public sector (since no one strictly prefers public education in the former case). Given our interest in the empirically relevant case with both sectors active and knowing equilibrium with a superintendent that chooses private school effectively shuts down the public sector, we focus the analysis on equilibrium with the elected candidate sending his child to public school. 16

\footnotetext{
${ }^{16}$ To be clear, we are not ruling out equilibrium with an inactive public sector, rather such equilibria do not arise in the empirically motivated parameterizations we examine. We also note that, when we introduce households
} 
Now consider Proposition 1b. A household that prefers public education has utility $U(y(1-t), g)$ implying their preference for $v$ and $y_{m}$ is indirect, only influenced by the effects of these variables on the government budget constraint. The fact that utility is strictly decreasing in $t$ and $(2 \mathrm{~A})$ is the relevant budget constraint implies the result. This establishes a conditional unanimity property, viz, conditional on $g$ and conditional on attending public school for that $g$, public school attendees are unanimous in their preference over $t, v$, and $y_{m}$. This conditional unanimity property plays an important role in our establishment of necessary conditions for equilibrium and in frequently overcoming the existence problems that are characteristic of multidimensional voting problems. For the analysis below, let $\underline{t}(g)$ denote the minimal $t$ in Proposition $1 \mathrm{~b}$, and let $\underline{v}(g)$ and $\underline{y}_{m}(g)$ denote the associated voucher and maximum income eligible for the voucher. When a candidate intending to attend public school proposes a policy $\left(g, t, v, y_{m}\right)$ that candidate then proposes $\left(g, \underline{t}(g), \underline{v}(g), \underline{y}_{m}(g)\right)$. All who would choose public school under the candidate's proposal are in agreement that $\left(\underline{t}(g), \underline{v}(g), \underline{y}_{m}(g)\right)$ are best given the proposed $g$.

Proposition 1c contains the key elements of equilibrium. It is clearer to discuss 1c(ii) first. The incentive of a superintendent who attends public school to choose a voucher is to induce students to exit the public sector and loosen the government budget constraint. A potential cost is subsidization of students that would choose private sector schools with no voucher. Maximizing the number of students that take a voucher without unnecessarily subsidizing any students requires providing the voucher to all but only students with incomes below the income bound above which students would attend private school with no voucher, i.e., $y_{m}=y_{T}(t, 0, g)$. Thus, given a voucher, targeting is optimal.

Regarding $1 \mathrm{c}(\mathrm{i})$, increasing the voucher above 0 is always optimal because it carries the benefit of inducing some households that would attend public school to switch to the private sector, relaxing the budget constraint, without any cost under optimal targeting. Any benefit would, however, disappear if the voucher is raised to the level of public expenditure.

Proposition 1c(iii) regards voting coalition and requires a bit more discussion. Equilibrium has an element of the "ends against the middle" voting coalitions found in Epple and Romano (1996a). ${ }^{17}$ Consider Figure 2, which shows $\underline{t}(g)$, again equal to the minimum $t$ written as a function of the $g$ preferred by households that attend public school. ${ }^{18}$ This function is obviously upward sloping, since $t$ is the minimum value that would result in $g$ public expenditure. Figure 2 depicts the equilibrium values of $(g, t)$ as a tangency between an indifference curve in the $(g, t)$ plane of the winning candidate and $\underline{t}(g)$. As one moves along $\underline{t}(g)$, the suppressed values of $v$ and $y_{m}$ change, these the values that minimize $t$ given $g$ (by Proposition 1b). The preferred $(g, t)$ of any household that would send their child to public school corresponds to a tangency between an indifference curve $U(y(1-t), g)=$ const.

with strong religious preference, we sometimes find preferred policies of some types that send their child to private school having active public and private sectors. However, these types are not elected.

${ }^{17}$ See also Glomm and Ravikumar (1998) and Epple and Romano (1996b).

${ }^{18}$ The domain of $\underline{t}$ consists of the values of $\mathrm{g}$ that are consistent with a public-private equilibrium assuming some household that prefers public school gets to choose the policy vector. Having noted this, our focus in the analysis that follows is on $\underline{t}$ in the vicinity of the political equilibrium. 


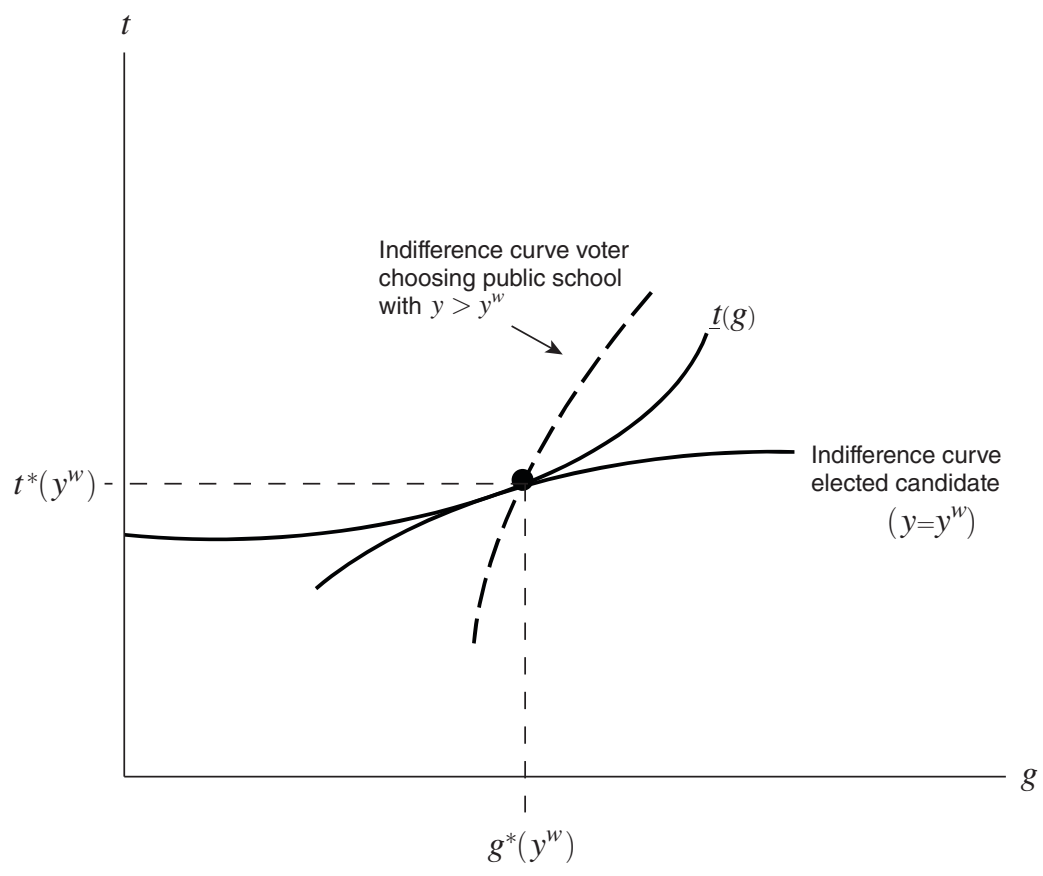

Figure 2. Voting Preferences

and $\underline{t}(g)$, along with the corresponding values of $\underline{v}(g)$ and $\underline{y}_{m}(g)$. Recalling that $y^{w}$ denotes the income of the elected candidate and letting * indicate preferred values, the equilibrium policy values are then $\left[g^{*}\left(y^{w}\right), t^{*}\left(y^{w}\right), v^{*}\left(y^{w}\right), y_{m}\left(y^{w}\right)\right]$ $=\left[g^{*}\left(y^{w}\right), \underline{t}\left(g^{*}\left(y^{w}\right)\right), \underline{v}\left(g^{*}\left(y^{w}\right)\right), \underline{y}_{m}\left(g^{*}\left(y^{w}\right)\right)\right]$.

At this point it is useful to introduce a relatively simple example to illustrate properties of equilibrium. The example is taken from Section IV and assumes no religious preferences, consistent with the analysis so far. Here we summarize the elements of the example, deferring the details of the calibration to Section IV. Household income is lognormal, with median $\$ 35,823$ and mean $\$ 48,382$ (as in Milwaukee in 2010). Household utility is CES, specifically, $U=\left[0.105 q^{-0.545}+0.895 x^{-0.545}\right]^{-1 / 0.545}$. Each household has 0.48 schoolaged children. The elected superintendent has income equal to $\$ 20,600$. The equilibrium policy vector is given by $\left[g^{*}, t^{*}, v^{*}, y_{m}^{*}\right]=[\$ 14,433,11.54$ percent, $\$ 9,022, \$ 78,388]$. Figure $3 \mathrm{~A}$ shows school type choice in equilibrium and local voting preferences as a function of household income.

Consider the local preferences over potential candidates of households with $y \neq \$ 20,600$. The logic in identifying voting coalitions is that equilibrium must be a local equilibrium, meaning no candidates with income in the vicinity of $y^{w}$ would defeat $y^{w}$ should they choose to run. Using Assumption 1, the indifference curves of households that choose public schools steepen as income rises. Thus, among these households, higher (lower) income ones would choose higher (lower) $g$ and $t$ if elected. Then, among these households, any that are richer (poorer) than the elected household would prefer to elect a marginally richer (poorer) household than the 


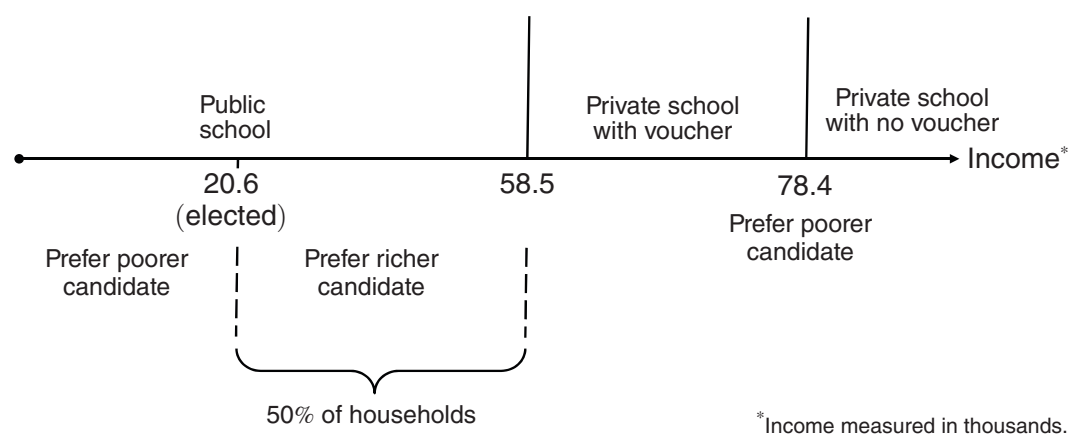

Figure 3A. School and Local Voting Preference: No Religious Types

elected superintendent. In the example, all households with income below $\$ 58,533$ choose public school. Those with income below $\$ 20,600$ prefer lower $(g, t)$ and a lower income candidate, while those with income on $(\$ 20,600, \$ 58,533)$ prefer higher $(g, t)$, and thus a higher income candidate.

Now consider the local preferences of any household who in equilibrium sends their child to private school while not qualifying for the voucher; i.e., with $y \geq y_{T}\left(t^{*}\left(y^{w}\right), 0, g^{*}\left(y^{w}\right)\right)=y_{m}^{*}$, the latter income equal to $\$ 78,388$ in the example. These households have utility $\max _{s \geq 0} U(y(1-t)-s, s)$, and are then locally indifferent to the values of $\left(v, g, y_{m}\right)$, but with preference for a lower tax. Thus, they would vote for a candidate with marginally lower income than the elected one.

Last are households who qualify for and take the voucher, those with income on $\left[y_{T}\left(t^{*}\left(y^{w}\right), v^{*}\left(y^{w}\right), g^{*}\left(y^{w}\right)\right), y_{T}\left(t^{*}\left(y^{w}\right), 0, g^{*}\left(y^{w}\right)\right)\right]$, equal to $[\$ 58,533, \$ 78,388]$ in the example. All of the latter households also prefer a locally lower tax, thus a locally poorer candidate than the elected one. Thus, the computed equilibrium has the ends-against-the-middle property. But the local preference of the set of households getting the voucher is not general. Writing their utility as a function of $g$, equal to $U^{v}(g) \equiv \max _{s \geq 0} U(y(1-\underline{t}(g))-s, s+\underline{v}(g))$, their local preference for a change in $g$ and thus candidates depends on the sign of

$$
U^{v^{\prime}}(g)=-y U_{x} \underline{t}^{\prime}(g)+U_{q \underline{\underline{v^{\prime}}}}(g) .
$$

If the derivative is negative (positive), then such a household's local preference is for a lower (higher) $g$, and thus $t$, implying preference for a candidate with marginally lower (higher) income. A Corollary of Proposition $1 c($ iii) is that equilibrium has the ends-against-the-middle property if the expression in (4) has a negative sign (in which case $\mathbf{Y}^{+}$is empty). However, if the equilibrium voucher increases with $g$, then these households face a tradeoff. A higher $g$ implies a higher tax rate, but then also a higher voucher. Signing $\underline{v}^{\prime}$ theoretically without more structure is infeasible, but we find that it is positive in the example and as parameters vary in our extended quantitative analysis in Section IV. The preference for lower $g$ and $t$ in our quantitative analysis is because the first effect in (4) outweighs the second. The statement of Proposition 1c(iii) allows for exceptions, which would imply more complex voting coalitions. 


\section{B. Existence of Equilibrium: Theory}

Existence of equilibrium requires existence of a Condorcet winner among households that might stand for election. We show existence of a Condorcet winner over a large parameter space in Section IV, but we also show that one may not exist. The availability of a private schooling alternative can disrupt equilibrium. The problem of existence of majority choice equilibrium with mixed public-private provision is a fairly long-standing issue and arises even without vouchers. For the moment, consider the same model, with a private alternative, but without vouchers allowed. Then the policy vector is bivariate, consisting of $(g, t)$. Two approaches to showing existence of majority choice equilibrium in such problems have been employed. One is to substitute in the government budget constraint to reduce the problem to voting over one variable, here $g$ or $t$, and then show the reduced form utility function is single-peaked allowing application of Black's Theorem (1948). However, Stiglitz (1974) showed this approach fails as a result of voters being able to switch between the public and private sectors as policy varies. ${ }^{19}$ The second approach is to show the effective utility function $\max \left[U^{P}, U^{R}\right]$, with no voucher if the private alternative is chosen, satisfies single-crossing in the $(t, g)$ plane; i.e., the slope of the indifference curves are monotonic in income. However, Epple and Romano (1996a) show this approach fails under Assumption 1, again due to sector switching. Introducing vouchers and targeting does not help to imply existence, rather it adds the Plott-dimensionality element to the existence problem. The citizen candidate approach helps to resolve the dimensionality problem by reducing the set of policies over which households effectively vote. Moreover, interestingly, those that choose public school for the preferred policy of a household that itself would choose public school share the same preference for the values of $\left(v, y_{m}\right)$ by Proposition $1 \mathrm{~b}$. In turn, for these households, we are effectively back to two dimensions of policy, specifically over $(g, \underline{t}(g))$. This provides the potential to employ single-crossing to show existence, but for the presence of those that choose private school in some preferred allocations. One way then to obtain existence based on these ideas is to restrict those that can vote and stand for election to those that would always choose public school for all preferred policies of the electorate, as we show in the Appendix.

Enfranchising everyone, establishing general sufficient conditions for existence of majority choice equilibrium is futile, given the private school alternative disrupts single-peakedness and single-crossing even in the simple model with no vouchers. With very strong restrictions preferences, one can obtain existence with everyone in the electorate. If $U(\cdot)$ is Cobb-Douglas, the limiting case of Assumption 1, then majority choice equilibrium exists so long as a majority would choose public school if elected. This is because preferences over $\left(t, g, v, y_{m}\right)$ are the same for everyone choosing public school. The problem with this case in our opinion is that assuming the same policy preferences for all those in public school is too restrictive. ${ }^{20}$

\footnotetext{
${ }^{19}$ In Section IVD, we show how school-sector switching might disrupt equilibrium in our model.

${ }^{20}$ One can also obtain existence results with weaker restrictions on the electorate if Assumption 1 is reversed to have the derivative decrease with $y$. Again, we find this unappealing given empirical estimates about preferences for schooling expenditure that support Assumption 1 (see footnote 4).
} 
But none of this implies general failure of existence! Rather, quantitative analysis is needed if one is to examine interesting cases. Our main strategy concerning existence is to use the necessary conditions of Proposition 1 for existence of a Condorcet winner, which permit us to identify the potential equilibrium and go on to check numerically if it is in fact an equilibrium. To determine whether equilibrium exists quantitatively, we use Proposition 1c(iii) to identify the prospective candidate $y^{w}$ and then confirm that no household $y$ exists in the population with preferred policy that is strictly majority preferred to $y^{w}$ 's preferred policy. This requires finding policies preferred by all household types. Proposition 2 summarizes the characteristics of policies that any household might prefer. Using Assumption 2 and Assumption 8, we can restrict attention to three types of policies.

PROPOSITION 2: A household that chooses the policy vector and itself chooses public school follows the policy described in Proposition 1. A household $y$ that chooses the policy vector and itself chooses private school either: $(i)$ chooses $t=g=v=0$ with optimal private consumption; or (ii) sets $v=g$, with $y_{m}=\max \left[y, y_{T}(t, 0, g)\right], t$ satisfying $(2 B)$, and with $v$ solving:

$$
\begin{gathered}
\max _{v, t, y_{m}, g} U^{R}(v) \\
\text { subject to } y_{m}=\max \left[y, y_{T}(t, 0, g)\right] ;(2 B) ; \text { and } v=g .
\end{gathered}
$$

Assuming a household choosing private school faces a strictly quasi-concave optimization problem, policy type $(i)[(i i)]$ is optimal if $y>[<] Y / F(y) .{ }^{21}$

Proof is in the Appendix. In our quantitative analysis, we identify households with the three possible policy-type preferences. By now, the elements of policy preferred by a household that sends their child to public school are clear. These are not-too-rich households. In the example above, all households with income less than $\$ 42,150$ fall into this group. Sufficiently rich households, if elected, would choose private school and provide no public funding because they face a high tax price (Policy (i) in Proposition 2). In the example, these are households with income of at least $\$ 63,050$. The alternative policy in (ii) is subtler. Such a household sets and takes a voucher that it supplements, while obviously choosing $y_{m}$ to make itself eligible for the voucher. Keeping in mind $g$ is not allowed to be below $v$, then choosing $g$ equal to $v$ minimizes taxes. To minimize the tax rate with respect to $y_{m}$, household with income $y$ chooses $y_{m}=\max \left[y, y_{T}(t, 0, g)\right]$, since this maximizes the number of households that attend private school with no voucher (subject to household $y$ itself getting the voucher). If $y<y_{T}(t, 0, g)$, setting $y_{m}$ equal to $y_{T}(t, 0, g)$ is Pareto Improving relative to a lower income threshold, and then adopted by the Benevolence Assumption 8. Under such policy, no households actually attend public school, but the option is there. A household that chooses this type of policy obtains a tax subsidy from the households that are ineligible for the voucher, while using the flexibility

\footnotetext{
model.

${ }^{21}$ If $y=Y / F(y)$, both policies are optimal. The quasi-concavity restriction is satisfied in our computational
} 
of supplementing the voucher. ${ }^{22}$ In the example, households with income between $\$ 42,150$ and $\$ 63,050$ have such a policy preference. To confirm equilibrium, we compute the specific policy preference of all the households, and show none of these policies and thus alternative candidates are majority preferred to electing $y^{w}$.

\section{Religious Preferences}

The majority of private school students in the United States attend schools with religious affiliation, ${ }^{23}$ with various degree of religious instruction provided, such practice being illegal in US public schools. As US voucher programs generally permit students to use vouchers to attend religious schools (see Tables 1 and 2 in ERU), taking account of preference for religious schooling provides a more realistic model. To maintain tractability, we build this into the analysis in a simple way. Assume a proportion $\gamma$ of households have "strong religious preferences," sending their children to religious schools if they choose private school, while valuing religious schooling quality by $\kappa q, \kappa>1$. For such households, everything is the same as in the model above, except $\kappa q$ replaces $q$ if private school is chosen. We assume the same income distribution for the strongly religious and other households, though the theoretical model could be modified to allow different income distributions. ${ }^{24}$ Those who are not strongly religious might attend a religious school, but their perceived quality equals $q$. We typically refer to the strongly religious as just religious, and everyone else as nonreligious.

We summarize the effects on the analysis while providing the detail and proofs in the online Appendix. Note, too, the differences between the religious and other types are seen in the quantitative analysis in Section IV. Conditional on their school choice, private or public, local preferences for policy changes and thus alternative candidates are essentially the same for religious and nonreligious types, exactly the same if public school is chosen. Differences in choices and equilibrium stem from the fact that religious types are more inclined to choose private school and, in particular, the threshold income for choosing private school of religious types, denoted $y_{T}^{R}(t, v, g)$, is below the nonreligious threshold $y_{T}(t, v, g)$ for any $v$.

Proposition 1 is modified as follows. It is possible to have active public and private sectors with a household elected that chooses private school, as explained further below. Thus, Proposition 1a no longer holds. However, we continue to focus on cases with the elected candidate choosing public school. Proposition $1 \mathrm{~b}$ continues to hold because preferences of those choosing public school are the same

\footnotetext{
${ }^{22}$ Any such households must find it optimal to supplement the voucher. Otherwise, they could switch to public school with the same quality, and then follow the policy of a household that prefers public school-lowering the voucher to obtain another tax subsidy from those that still take it. One might also think the household would be better off by instead of supplementing the voucher switching to public school while increasing $g$, substituting tax funding for their own private funding of the voucher supplement. But this would imply a higher $g$, more households that do not get a voucher moving into public schools, and thus a lower subsidy from them.

${ }^{23}$ In 2009,80 percent of private school enrollment was in religious schools, with 43 percent of private enrollment in Catholic schools. (Values derived from Table 1 in Ewert 2013.)

${ }^{24}$ A 2009 survey by the PEW Research Center found that the income distribution of individuals who report being Catholic is very close to the income distribution for the overall US population. http://www.pewforum. org/2009/01/30/income-distribution-within-us-religious-groups/.
} 
for religious and nonreligious households. Proposition $1 \mathrm{c}(\mathrm{i})$ carries over by the same logic. Proposition 1c(ii) is modified to have $y_{m}$, the eligibility threshold for the voucher, equal to either $y_{T}^{R}(t, 0, g)$ or $y_{T}(t, 0, g)$, depending on parameters. Choosing the higher income threshold for voucher eligibility, $y_{T}(t, 0, g)$, provides vouchers to religious types with incomes $y \in\left[y_{T}^{R}(t, 0, g), y_{T}(t, 0, g)\right]$ who would attend private school with no voucher, increasing the tax rate. However, by choosing the lower income threshold $y_{T}^{R}(t, 0, g)$, tax saving from the latter households would arises because $v<g .{ }^{25}$

Regarding Proposition 1c(iii) on voting coalitions, keep in mind that those choosing public school in equilibrium with the same income have the same local policy and voting preferences whether religious or not. However, because religious types have stronger preference to attend private school, the sets of income types that choose public school generally differs. Let $f^{p u b}(y)$ denote the population density of nonreligious types that attend public school, equal to $(1-\gamma) f(y)$ if public school is chosen and 0 otherwise. Let $f^{p u b R}(y)$ denote the same for religious types, equal to $\gamma f(y)$ if public school is chosen and 0 otherwise. ${ }^{26}$ Those that choose private school and receive no voucher prefer lower $t$ (and care not about $g$ and $v$ ), whether religious or not. The sign of (4) again determines the local voting preferences of those that choose private school and receive a voucher. The equilibrium income sets for which this is positive or negative can differ between religious and nonreligious types, both because $U_{q}$ will differ and because the range of income of those that choose private school and get a voucher can differ. Let $\mathbf{Y}^{+}$denote the nonreligious income set that obtain a voucher and for which $U^{v^{\prime}}>0$, and let $\mathbf{Y}^{+R}$ denote the analogous set of religious households. The modified version of Proposition 1c(iii) follows.

PROPOSITION R1c(iii): Assuming equilibrium has a superintendent that chooses public school, $y^{w}$ must satisfy: $\int_{y \geq y^{w}}\left[f^{p u b}(y)+f^{p u b R}(y)\right] d y+\int_{\mathbf{Y}^{+}}(1-\gamma) f(y) d y+$ $\int_{\mathbf{Y}^{+R}} \gamma f(y) d y=0.5$; with households in the latter integrations preferring a marginally higher income candidate (other than $y^{w}$ ), and the remaining household preferring a candidate with marginally lower income.

The results about the types of policies that could arise closely tracks Proposition 2.

PROPOSITION R2: A household that chooses the policy vector and itself chooses public school follows the policy described in the modified version of Proposition 1. A household $y$ that chooses the policy vector and itself chooses private school either: (i) chooses $t=g=v=0$ with optimal private consumption; or (ii) sets $v=g>0$, with $y_{m}=\max \left[y, y_{T}^{R}(t, 0, g)\right]$, $t$ satisfying

$$
g\left[\int_{y_{\min }}^{\max \left[y, y_{T}^{R}\right]} \gamma f(y) d y+\int_{y_{\min }}^{\max \left[y, y_{T}\right]}(1-\gamma) f(y) d y\right]=t Y,
$$

\footnotetext{
${ }^{25}$ That the equilibrium eligibility threshold is one of these two values depends on our assumption that the income distributions of both types are the same. Otherwise, it is possible for the eligibility threshold to fall in the range $\left[y_{T}^{R}(t, 0, g), y_{T}(t, 0, g)\right]$.

${ }^{26}$ The ranges of income over which public school is chosen vary with parameters and are detailed in the online Appendix. Figure 3B below provides an example.
} 
and with $v$ solving

$$
\begin{gathered}
\max _{v, t, y_{m}, g} U^{R}(v) \\
\text { subject to } y_{m}=\max \left[y, y_{T}^{R}(t, 0, g)\right] ;(5) ; \text { and } v=g .
\end{gathered}
$$

Assuming a household choosing private school faces a strictly quasi-concave optimization problem, policy type $(i)[(i i)]$ is optimal if $y>[<] Y / F(y)$.

If the $v=g>0$ policy is chosen, then either the elected household's own income is chosen as the eligibility threshold or the religious type's threshold for attending public school with no voucher is chosen (as proved in the online Appendix). The budget constraint (5) for this policy is adjusted to account for both religious and nonreligious types. In finding equilibrium, we must consider both religious and nonreligious types as potential candidates. Note that, in cases where policy type (ii) arises, any nonreligious households with $y \in\left(y_{m}, y_{T}(t, 0, g)\right)$ are ineligible for the voucher and would choose public school. This is the case noted above that has an active public and private sector in spite of policy being set by a household that chooses private education.

\section{Quantitative Analysis}

\section{A. Computational Model}

The quantitative analysis serves to demonstrate existence, illustrate properties of equilibrium, and apply the model to the case of the Milwaukee school district. The Milwaukee voucher program is the longest running and largest US public program for nondisabled students, introduced in 1990, with 24,027 students taking vouchers in 2012. ${ }^{27}$ It has properties typical of the US programs, with current eligibility requiring household income below 300 percent of the poverty line. Vouchers can be used at religious schools. In 2012, 112 private schools took voucher students.

To perform the analysis, we must calibrate the household utility function, the income distribution, the proportion of religious types $\gamma$, and the value of the latter's preference parameter for religious instruction $\kappa$. We assume the income distribution is lognormal. The city of Milwaukee is a relatively poor area. The Milwaukee household income distribution in 2010 had median and mean income of $\$ 35,823$ and $\$ 48,382$ respectively, pinning down the two parameters of the assumed distribution. ${ }^{28}$

We adopt a CES utility function

$$
U=\left[\beta q^{-\rho}+(1-\beta) x^{-\rho}\right]^{-1 / \rho} .
$$

\footnotetext{
${ }^{27}$ Values for the Milwaukee voucher program are taken from ERU.

${ }^{28}$ Income values are from US Census Bureau Quick Facts. These imply the mean of the log income equals 10.486 with standard deviation 0.775 .
} 
TABle 1 -Empirical and Model Values

\begin{tabular}{lcccr}
\hline \hline & Voucher & $\begin{array}{c}\text { Eligibility } \\
\text { threshold }\end{array}$ & $\begin{array}{c}\text { Public expenditure } \\
\text { per student }\end{array}$ & $\begin{array}{r}\text { Percent } \\
\text { in public }\end{array}$ \\
\hline Empirical & $\$ 6,442$ & $\$ 66,150$ & $\$ 15,237$ & 73.7 \\
Baseline calibration & $\$ 8,824$ & $\$ 77,447$ & $\$ 14,297$ & 72.3 \\
No religious households & $\$ 9,022$ & $\$ 78,388$ & $\$ 14,433$ & 73.7 \\
Voucher not allowed & - & - & $\$ 15,884$ & 87.5 \\
\hline
\end{tabular}

We choose values of $(\beta, \rho, \gamma, \kappa)$ so that equilibrium exists and approximates the empirical values in 2010-2011 of public school attendance in Milwaukee (73.7 percent), per student expenditure in public schools $(\$ 15,327)$, the amount of the voucher $(\$ 6,442)$, and the voucher qualification threshold $(\$ 66,150) .{ }^{29}$ See Table 1. The parameter values are $(\beta, \rho, \gamma, \kappa)=(0.105,0.545,0.15,1.15)$. We further adjust for the fact that the number of school-aged children per household is less than 1, equal to 0.48. ${ }^{30}$ All the expenditure values we report are per child values.

Finding equilibrium requires identification of the winning candidate, that candidate's preferred policy vector, and the associated equilibrium choices of everyone, religious and nonreligious. The local conditions for equilibrium help in identifying the winning candidate. To verify equilibrium, we must show that the winning candidate's policy is a Condorcet winner matched against every other household's preferred policy. Policies proposals of nonwinning candidates are of independent interest, too, illustrating the various types of policies that can arise in Proposition R2.

The program to compute equilibrium first selects a dense income grid of both religious and nonreligious types representing the citizen candidates. ${ }^{31}$ It then calculates a large set of feasible policies, which includes every feasible policy $\left(t, g, v, y_{m}\right)$ that could potentially be chosen as a proposal by every one of these citizen candidates (with choice of public or private school, with choice of different voucher amounts, etc.). The restrictions imposed by Propositions 1 (modified for the presence of religious types) and R2 make this manageable. For each candidate, the utility maximizing element from this large set becomes their proposal. The program then draws a large random sample of voters from the income distribution for both religious and nonreligious types. Starting from a guess of the winner proposal (based on Proposition R1c(iii)) — call this the contender-and a local alternative proposal, it calculates the fraction of voters that receive a higher utility under the alternative proposal. If this fraction exceeds 0.50 , the alternative proposal becomes the contender and this repeats until all proposals are considered. Winning this series of voting is a necessary condition to be a Condorcet winner. The winner proposal is then paired against every other proposal. If it defeats all alternatives, then it is the

\footnotetext{
${ }^{29}$ Public attendance is computed using Milwaukee Public Schools 2010-2011 District Report Card and the Wisconsin Department of Public Instruction website. Per student public expenditure uses the Wisconsin School District Performance Report (Wisconsin Department of Public Instruction Website). The federal poverty line for a family of 4 in 2010 equaled \$22,050 (HHS Poverty Guidelines, US Department of Health and Human Services).

${ }^{30}$ The city of Milwaukee had 229,555 households in 2010 (Census Quick Facts), with 29,024 students attending private schools (Wisconsin Department of Public Instruction) and 81,372 students attending public schools (Milwaukee Public Schools District Report Card).

${ }^{31}$ We here provide a brief summary of the program, with a more detailed description in the online Appendix.
} 

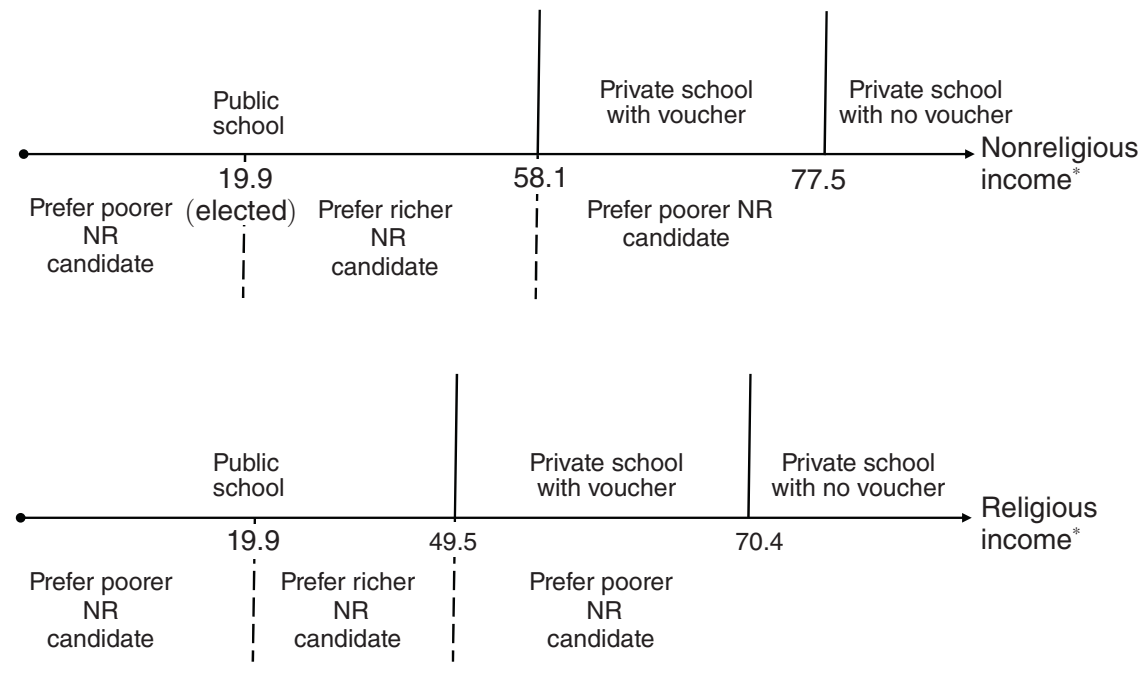

*Income measured in thousands.

Figure 3B. School and Local Voting Preference: Full Model

Condorcet winner. If it is defeated by the proposal of some other candidate, then there is no Condorcet winner, and no citizen-candidate equilibrium exists.

\section{B. Baseline Analysis}

Turning now to our findings in the baseline equilibrium, refer to Table 1 . We find a voucher equal to $\$ 8,824$, public per student expenditure equal to $\$ 14,297$, the voucher eligibility threshold equal to $\$ 77,447$, and with 72.3 percent of students attending public school. The eligibility threshold is that for nonreligious households, the higher $y_{T}(t, 0, g)$ of the two potential theoretical thresholds. ${ }^{32}$ From Table 1, we see that the model performs reasonably well, though somewhat overpredicting the amount of the voucher and under-predicting public expenditure. The winning candidate is nonreligious and has income equal to $\$ 19,900$.

Figure 3B shows the equilibrium school choices and local voting preferences of nonreligious and religious types by their incomes. The nonreligious and religious types' thresholds for attending private school with a voucher are, respectively, $y_{T}(t, v, g)=\$ 58,137$ and $y_{T}^{R}(t, v, g)=\$ 49,485$. All the respective types with incomes above these thresholds attend private school, those eligible for the voucher of course taking it.

To understand the local voting preferences summarized in Figure 3B, refer to Figures 4 and 5. Figure 4 shows the preferred policy values of $g$ and $v$ of all candidates by income and by whether the candidate is strongly religious or not.

\footnotetext{
${ }^{32}$ The lower potential threshold $y_{T}^{R}(t, 0, g)=\$ 70,377$.
} 


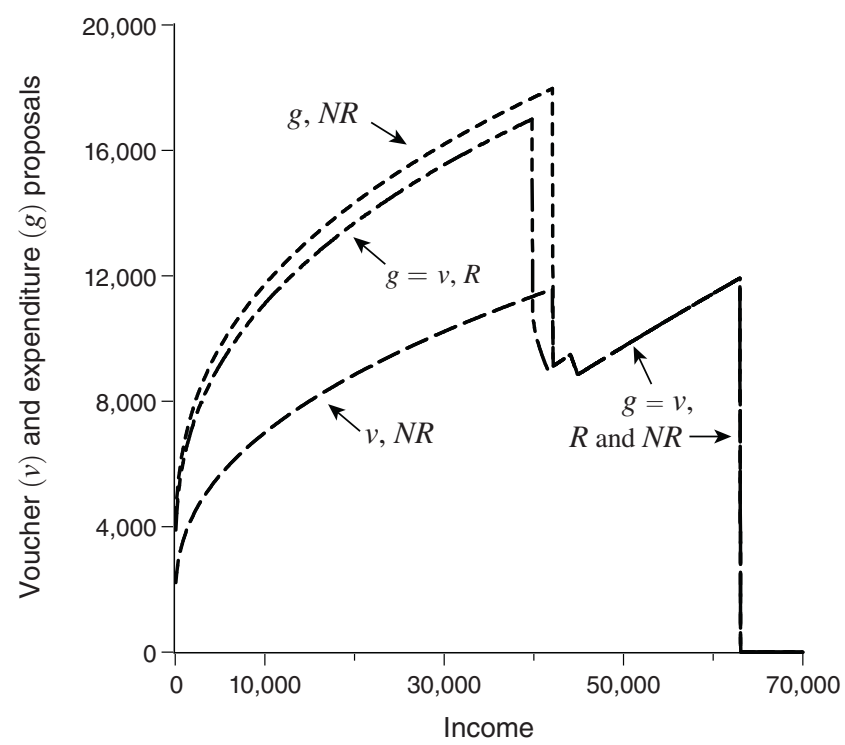

Figure 4. Voucher and Expenditure Proposals as a Function of Income for Religious (R) ANd Nonreligious (NR) CANDidates

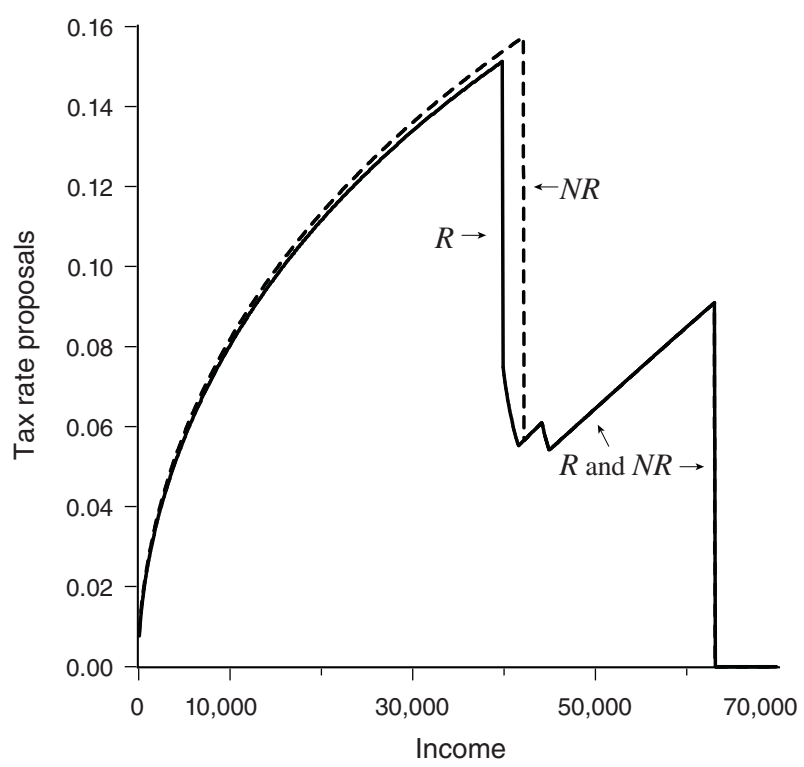

Figure 5. Tax Rate Proposals as a Function of Income for Religious (R) and Nonreligious (NR) CANDIDATES

Figure 5 shows the same for the tax rate. The preferred $g$ and $v$ of nonreligious types with income near the winning candidate are increasing with income (Figure 4), thus the same for the tax rate (Figure 5). Using Proposition R2, those in public school with income above (below) the winning candidate have local preference for a nonreligious candidate with higher (lower) income. All those who attend private school with no voucher prefer a lower tax rate, hence, prefer a nonreligious 
candidate with lower income. For those who are in private school with a voucher, we do not know theoretically whether a higher or lower income nonreligious candidate is locally preferred because the voucher that would be chosen increases with the candidate's income (Figure 4). Computationally we find all those who get a voucher prefer a lower income candidate to reduce their taxes, in spite of the implied lower voucher. These households then are in the coalition preferring a lower income nonreligious candidate. The equilibrium voting coalition then has a version of the "ends-against-the-middle property" in Epple and Romano (1996a), with highand low-income households opposing middle income households, these coalitions though varying some with religious preference.

Policy preferences of losing candidates are interesting. The three alternative policies in Proposition R2 would be chosen by some type, if in power. Consider, first, nonreligious candidates. As seen in Figure 4, nonreligious candidates with income $\$ 42,100$ or below would, if elected, choose public school and a $g>v>0$ regime, with $g$ and $v$ increasing with income. We also find they would choose the higher nonreligious income threshold for voucher eligibility, this threshold is also increasing with the winning candidate's income and preferred policy. 33 Figure 6 shows the implication of enacting these alternative policies for the proportion attending public school, this graph again showing the implied value for any winning alternative candidate by income and depending on whether the candidate is religious or not.

For income of a nonreligious winning candidate in the range $\$ 42,200$ to $\$ 63,000$, the preferred regime changes to that with $v=g>0$. Here the winning candidate would send their child to private school and supplement the voucher. The eligibility threshold would then be set to the lower threshold value, $y_{T}^{R}(t, 0, g)$, also equal to the income of the winning candidate. This is a kind of corner solution where the winning candidate makes himself just eligible for the voucher, while obtaining a tax supplement to finance the voucher from those who attend private school and are ineligible for the voucher. ${ }^{34}$ It might seem counterintuitive that these households want to finance some but not all of their private education through taxation, but such partial coverage of their education cost is preferred by households when the following situation arises. Increasing $v=g$ and the tax to finance would increase the tax outlay by more than the increase in $v$ because the associated increase in $g$ would induce more voucher-ineligible households to switch from private to public school. Reducing $v=g$ and decreasing the tax directly lowers $v$ by more than the household saves in taxes.

Once the income $y$ of the winning candidate gets high enough, above $Y / F(y)$ by Proposition R2, it becomes optimal to choose the $g=v=t=0$ regime. Here, any taxation to finance the privately chosen education is not worth it in spite of the

\footnotetext{
${ }^{33}$ These thresholds are not reported here to save space. Contact the authors for this information. Keep in mind the entire equilibrium changes as the income of the winning candidate changes.

${ }^{34}$ For $v=g$ policies, the voucher faced by a winning candidate with income $y$ as a function of the tax rate $t$ is given by the fixed point of $v=t Y / F\left(\max \left[y, y_{T}^{R}(t, v, v)\right]\right)$. Letting $V(t)$ denote the fixed point, the function has a kink at $y=y_{t}^{R}$. The policy optimum for a range of household incomes occurs at this kink in our calibration, where one must keep in mind that $y_{T}^{R}$ is endogenous to the household's choice of $(t, v)$.
} 


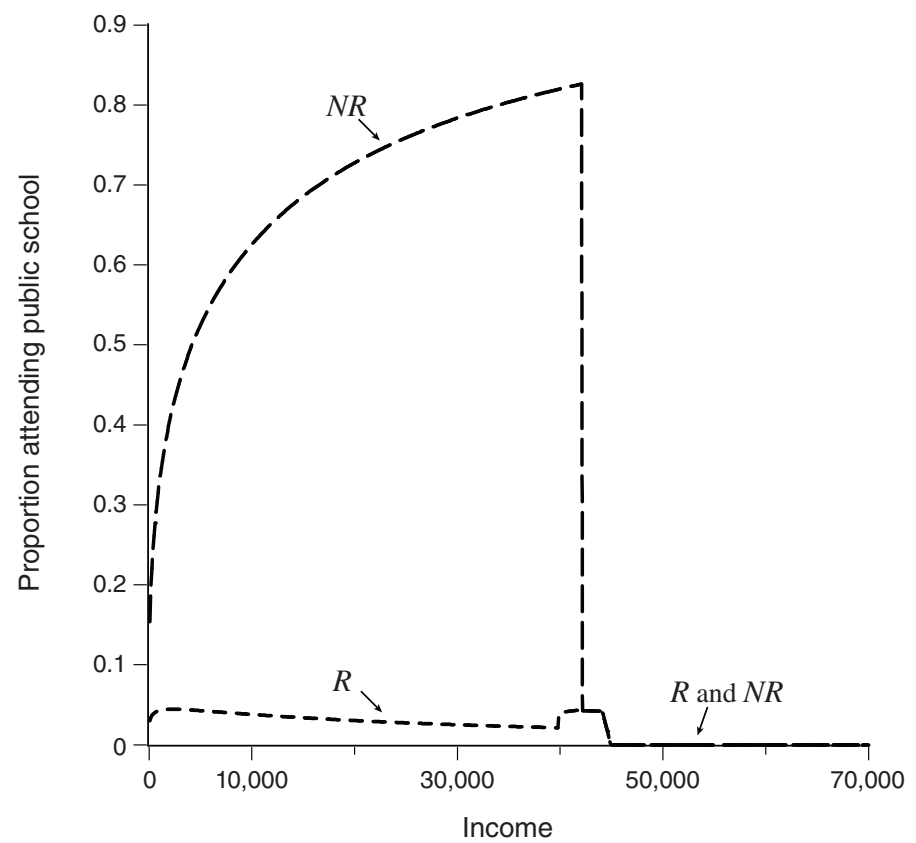

Figure 6. Proportion of Students Attending Public School for Proposals of Religious (R) and NonReligious (NR) HouseHoldS

subsidy from those who would be made ineligible for the voucher (i.e., those with income higher than the winner).

In our calibration, a religious type, if elected, would always send their child to private school. If an elected religious type has income below $\$ 39,900$, they would choose a $v=g$ regime with complete finance of their private education through taxation. For income from $\$ 39,900$ to $\$ 63,000$, a winning religious candidate continues to choose a $v=g$ regime, but where they supplement their private education, financing only part of it through taxation (the analogous corner solution above). Above \$63,000, like nonreligious households, these winning candidates would choose private education with own finance; i.e., with the $v=g=t=0$ regime. The income threshold where this occurs is the same as for nonreligious households since, given private education is chosen, how it is financed is purely a fiscal decision. For the same reason, for any incomes where both a religious and nonreligious winning candidate prefers private education, the chosen policy choices $\left(t, v, g, y_{m}\right)$ are exactly the same (as seen in Figures 4 and 5). Religious types in power do choose private education over a wider range of income, for all incomes in this calibration.

Figure 7 shows the proportional vote favoring the proposal (denoted $S$ ) of the winning candidate if matched against any other candidate, the vote as a function of the income of the candidate and whether the candidate is religious or not. This proportion must never be below 0.50 , and, of course, equals 0.50 if the "opposing candidate" is nonreligious with the same income as the winner. The analysis displayed in Figure 7 verifies the equilibrium. 


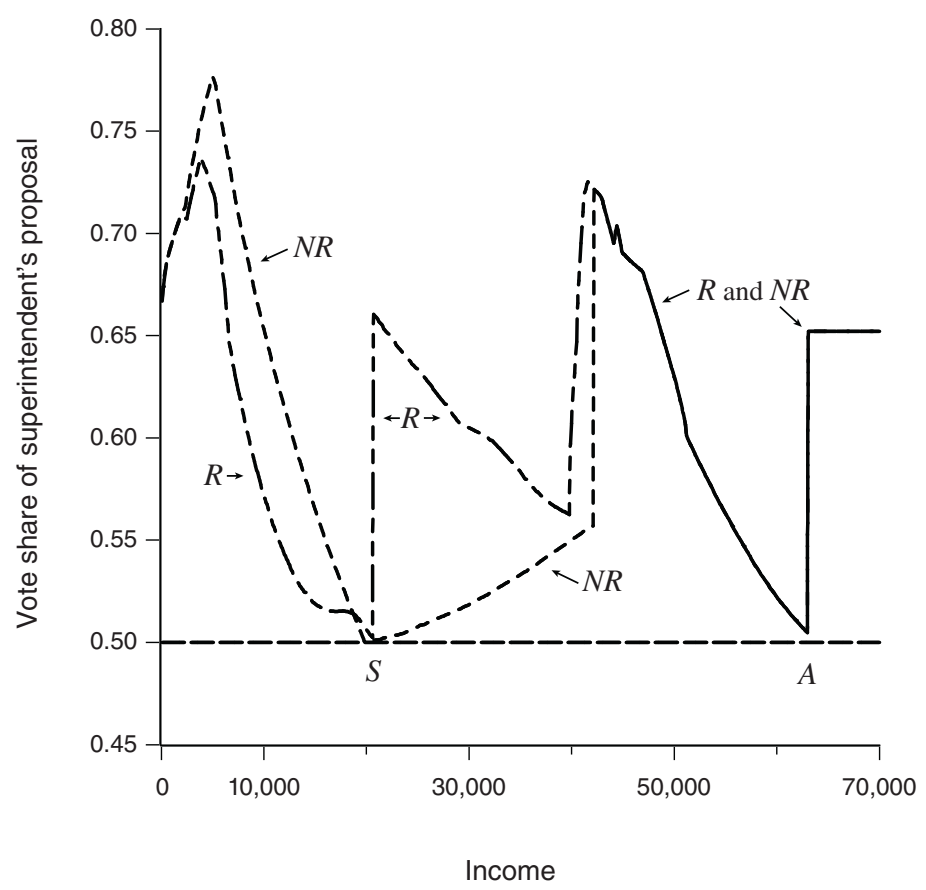

Figure 7. Vote Share of Superintendent's Proposal against Proposals of Religious (R) and NonReligious (NR) CANDIDATES

Observe from Figure 7 that the vote share for the winning candidate if matched against a poorer candidate is a few percentage points lower if that type is religious than if nonreligious. The value of $g$ chosen by a poorer religious type is little bit lower and the tax rate is slightly lower (see Figures 4 and 5). Due to the lower tax rate, richer households that do not get a voucher prefer the same-income (poor) religious type to the nonreligious type, as do very poor households in public school. However, the remaining households that would send their children to public school prefer the same income (poor) nonreligious type because of the somewhat higher public expenditure. In addition, those that are eligible for and take up a voucher prefer the religious types who would choose a substantially higher voucher (see Figure 4). For this low range of income of the two different types of candidates, the net effect is a preference for election of a religious type, so the elected candidate faces stiffer competition from religious types. As income of alternative candidates rises, the relative vote against a religious type rises sharply around an income of $\$ 20,700$, as shown in Figure 7. What happens here is that the religious type, if elected, would choose a lower public expenditure and a higher tax than the elected candidate, while a nonreligious type of the same income would choose a lower public expenditure but also a lower tax. Those that rely on the public expenditure for their full educational costs are then much more in favor of the nonreligious alternative candidate. Once income of alternative religious and nonreligious candidates enters the range where they would both choose private schooling their policy proposals converge 
as discussed above. When income reaches approximately $\$ 64,000$, both religious and nonreligious types propose zero public expenditure, and the vote against them relative to the winning candidate stays at 65.2 percent. The 34.8 percent of those that prefer the policy with no public expenditure consists of those that would themselves chose this policy (i.e., those with income exceeding $\$ 63,000$ equal to 23.3 percent of the population) and those with income high enough to be ineligible for the voucher but nonetheless favoring the policy because of its lower tax rate.

\section{Comparison to No Voucher}

Not allowing a voucher has substantial effects. Suppose no candidate is permitted to propose a voucher, so a winning candidate sets only $(g, t)$. Any household can still choose to attend private school of course, including schools offering religious instruction. In the baseline calibration, public school per student expenditure rises substantially, to $\$ 15,884$ if no voucher is allowed (see Table 1). ${ }^{35}$ Given the loss of the subsidy provided by the voucher, the tax rate must rise substantially to finance the increased public expenditure, specifically from 11.3 percent to 13.8 percent. With no voucher, the proportion attending a private school drops from 28 percent to 13 percent. What explains the substantial increase in public expenditure? The key is that the winning candidate has substantially higher income, $\$ 28,000$ rather than $\$ 19,900$. With fewer students in private schools, fewer favor lower taxation and the income of the winning candidate must rise to balance those that favor higher versus lower taxes and public expenditure.

This finding supports the concern of those that oppose vouchers because they will drain money from public schools. The explanation is, however, not the specious argument frequently expressed, which ignores the fact that vouchers are typically well below (marginal) per student public expenditure. Rather, allowing vouchers draws higher-income students into private schools, leading to stronger political support for a policy maker that favors lower taxation and expenditure.

It is interesting that, when equilibrium with a voucher exists, a large majority prefers the regime that allows vouchers even though, when vouchers are allowed, a majority of students consume less education. In our calibration, 81 percent favor the equilibrium that allows vouchers. Those that would get the voucher largely support the voucher regime. Those that are relatively wealthy and attend private school, receiving no voucher in either regime, prefer the voucher regime due to the lower tax. Likewise, less wealthy students in public schools in both regimes prefer the lower tax in the voucher regime. In fact, assuming existence, preference for the voucher regime holds generally.

PROPOSITION 3: Assume a citizen candidate majority choice equilibrium exists with no voucher allowed and with a targeted voucher allowed. Assume in the former equilibrium that some households choose private school. The equilibrium with

\footnotetext{
${ }^{35}$ Citizen candidate equilibrium with no voucher exists in the baseline calibration.
} 
targeted voucher is strictly majority preferred to the equilibrium with no voucher allowed.

The proof (in the Appendix) is easily summarized. With an income-targeted voucher below public school expenditure, one can find an allocation that reproduces public school expenditure in the no-voucher equilibrium, but with a lower tax rate. Everyone is strictly better off since those that choose public school or private school with no voucher are better off due to the lower tax rate and those that take up the voucher are better off by revealed preference. The equilibrium targeted voucher is majority preferred (or the same as) the latter regime, and so is majority preferred to the no-voucher regime. Given Paretian preference for some allocation with a targeted voucher, it is not surprising that a large majority prefer the equilibrium targeted voucher regime. We have varied incrementally the proportion of religious types from 0 to 0.15 , finding in all cases a large percentage of households gaining in moving from equilibrium with no voucher to equilibrium with the targeted voucher, that percentage varying between 80 and 84. Proposition 3 suggests that targeted voucher regimes should be pervasive, presuming existence of the latter. However, existence of equilibrium with a targeted voucher is not guaranteed, as we examine further next.

\section{Existence: Quantitative Analysis}

We have seen that equilibrium exists in some empirically relevant cases. One can ask, however, whether equilibrium will exist for a wide range of parameter values. We consider first the computationally more tractable case with no religious types. Thus, for the moment, set $\gamma=0$. The panels of Figure 8 show parameter spaces where equilibrium exists and does not. In the upper panel, we hold the parameters of the income distribution constant at baseline values and vary the parameters of the utility function. In the lower panel, we hold parameters of the utility function constant at the baseline values and vary the parameters of the income distribution. As one can see, equilibrium exists over a large parameter space, but also fails over a substantial parameter space.

Regarding the variation in the parameters of the utility function, the area where equilibrium does not exist and the omitted space with $\beta>0.45$ are not empirically relevant, though things are not so sanguine when we introduce religious types as discussed below. ${ }^{36}$ How and why equilibrium sometimes fails is an interesting issue. We have not examined this over the entire space of equilibrium failure, but for several examples, which we find all have the same character. Consider a typical example with parameters at point $\mathrm{A}$ in the upper panel of Figure 8 and refer also to Figure 9. A household with income of $\$ 19,900$ satisfies the locally balanced preference condition in Proposition 1c(iii), whom we refer to as the "local winner." A local winner must be elected if equilibrium exists. The local preferences of

\footnotetext{
${ }^{36}$ For values of $\beta>0.45$, our program tends to crash, and then it is extremely time consuming to find the cause and confirm whether or not equilibrium exists. Fortunately, such values are well beyond plausible values for this share parameter.
} 

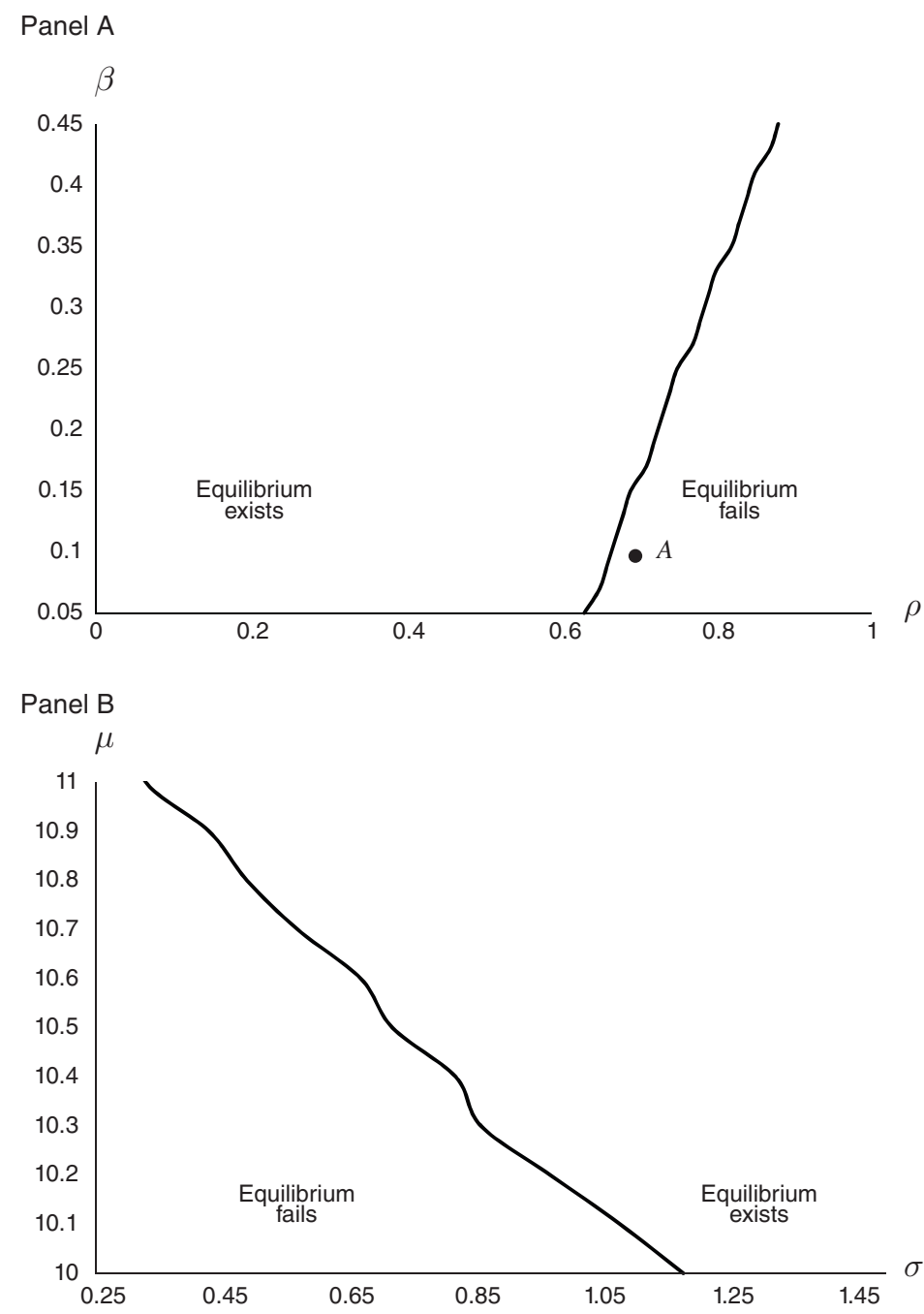

Figure 8. Existence and Existence Failure as Parameters Vary

voters for candidates with marginally higher or lower income are as indicated above the income line in Figure 9. These preferences satisfy the ends-against-the-middle property. A candidate with discretely higher income, specifically $\$ 21,000$, would defeat the local winner and disrupt equilibrium. The \$21,000-income household would choose public school if elected and choose discretely higher $g$, $t$, and $v$, while also increasing the voucher eligibility threshold $\left(y_{T}\right) \cdot{ }^{37}$ Voter preferences with this alternative proposal are shown below the income line in Figure 9. The higher $g$ and $t$ would induce a finite number of households to switch from private to public school. Some of the latter households, those with incomes between $\$ 56,745$ and $\$ 57,301$

\footnotetext{
${ }^{37}$ Recall that $y_{T}=y_{T}(t, 0, g)$, which is increasing in $t$ and $g$ by (1).
} 
Local preferences (ends against the middle)

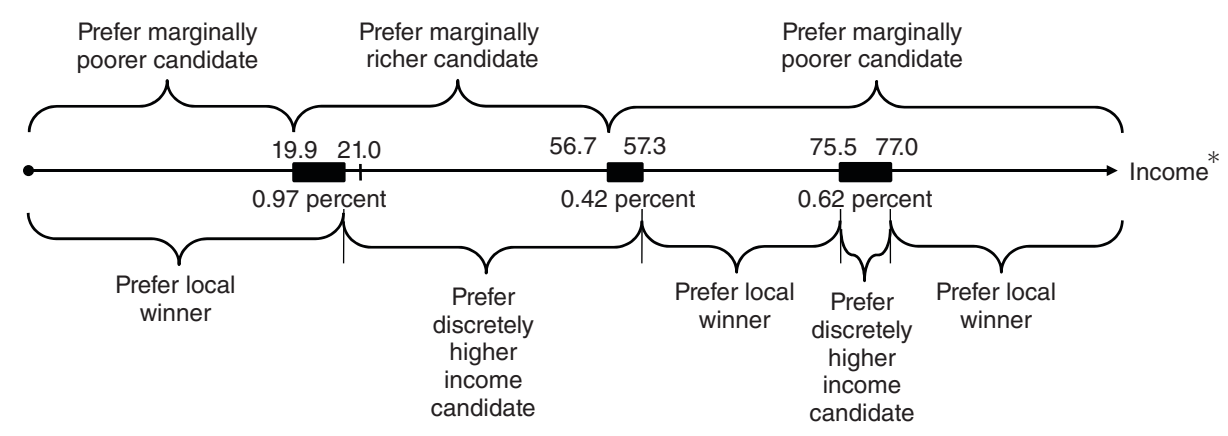

Global preferences (between local winner and discretely higher income candidate)

Figure 9. Local versus Global Preferences: Example of Existence Failure

Note: ${ }^{*}$ denotes income measured in thousands.

(0.42 percent of the population), would vote for the $\$ 21,000$-income household over the local winner, while they would vote against a household with marginally higher income than the local winner and stay in private school if the local winner or a marginally higher income household were elected. Their local preference is to vote against a higher income household than the local winner because they do not want a higher $t$ while in private school, but their global preference has them vote for the discretely higher income candidate that significantly increases $g$ and draws them into public school. Another group that would vote against a marginally higher income candidate than the local winner, but would vote for the $\$ 21,000$-income candidate, have income between $\$ 75,487$ and $\$ 77,028$ (0.62 percent of the population). These households choose private school if either candidate is elected, but become eligible for the voucher if the $\$ 21,000$ candidate is elected. For equilibrium to exist, these groups' preference reversal needs to be offset by households that prefer a marginally higher income household than the local winner, but would vote against the discretely higher $\$ 21,000$ income candidate. Households with incomes between $\$ 19,900$ and $\$ 20,433$, who attend public school if either candidate is elected, reverse their preference in this way because they favor a marginally higher $(t, g)$, but not the discretely higher $(t, g)$ because their preferences are not far from the $\$ 19,900$ (local winner) candidate's preferences. But their percentage is 0.97 , not enough to offset the other two groups that reverse preferences, and the discretely higher income candidate would defeat the local winner. Equilibrium fails; there is no local winner that is not defeated by a candidate with discretely higher income.

The other equilibrium failures we have examined to the right of the locus in the upper panel of Figure 8, as well as below the locus in the lower panel, have the same character: The candidate who is the local winner is defeated by a candidate with discretely higher income that would choose discretely higher $(t, g, v)$ and higher $y_{T}$, drawing from the private sector some students who would exhibit the described local-global preference reversal, along with those in private schools that become 
eligible for the voucher increase. The latter groups are a larger percentage than those in public school that flip their preference in the opposite way. Note that such preference reversals arise in the space of parameters where equilibrium exists when candidates with discretely different incomes are compared to the local winner, but, when equilibrium exists, the net reversals continue to support the local winner.

Connecting these existence failures to parameter values is complex because one must determine how the proportions of the three groups that reverse preferences are affected, which depend on different factors. Consider, again, the impact of changing the preference parameter $\rho$. The proportion of those that prefer a marginally higher income candidate than the local winner, but not discretely higher income candidates, increases as $\rho$ declines. As $\rho$ declines, the preferences of those in public school for $(t, g)$ vary less, so that they are resistant to significant policy changes. Thus, as shown in Figure 8, equilibrium exists for low to moderate values of $\rho$, this in the spirit of the existence result when $\rho=0$ and preferences are Cobb-Douglas. Increasing $\beta$ implies higher demand for educational quality, mainly affecting preference for educational expenditure whether choosing public or private school. The effects on the relative size of the groups that exhibit the local-global preference reversals are small, so the locus delineating the existence/nonexistence space in the $(\rho, \beta)$ plane is steep. Consider the narrow range of $\rho$ over which the locus in the upper panel of Figure 8 slopes upward. For such values of $\rho$, we find that increasing $\beta$ increases the relative size of the group in public school that are loath to electing a discretely higher income type, supporting existence of equilibrium, whereas reducing $\beta$ has the opposite effect. When one considers varying the parameters of the income distribution function, the weights on the three groups vary as the distribution shifts. Specifically, lower $\sigma$ and $\mu$, which both decrease the mean and variance of actual income, place more weight on the groups that are disruptive of equilibrium in the examples we have examined.

While we have shown above features of equilibrium failure that characterize the cases that we have investigated in the one-religious-type model, there may be other patterns of sector-switching and preference reversals that give rise to failure of equilibrium in the one-type model. We now return to the case with religious types, where we identify another possibility for equilibrium failure. We let the proportion of religious households vary, with the other parameters set at baseline values. As suggested above, for $\gamma \in[0,0.15]$, equilibrium exists and the equilibrium outcomes vary continuously with $\gamma$. We also find that equilibrium has the ends-against-the-middle property within religious and nonreligious types in all cases, as in the baseline case with voting coalitions illustrated in Figure 3B.

Increasing $\gamma$ above its baseline value gives rise to additional interesting findings. The effects are best understood by reference to Figure 7 and Figure 10 . Two points are labeled in Figure 7. Point $S$ denotes the proportional vote for the superintendent's proposal against itself, of course equal to 0.5. Point A denotes the alternative garnering the most votes against the superintendent's proposal. Referring to Figure 4, we see that the alternative A has $g=v$ and has the highest voucher proposed by any nonreligious candidate. The same proposal is made by a religious candidate with the same income. As we have already discussed, the proposal $\mathrm{S}$ is a Condorcet winner and, hence, defeats the alternative A. As the share of religious 
Panel A. Votes for proposals of nonreligious candidates against proposal of $y=\$ 63,000$

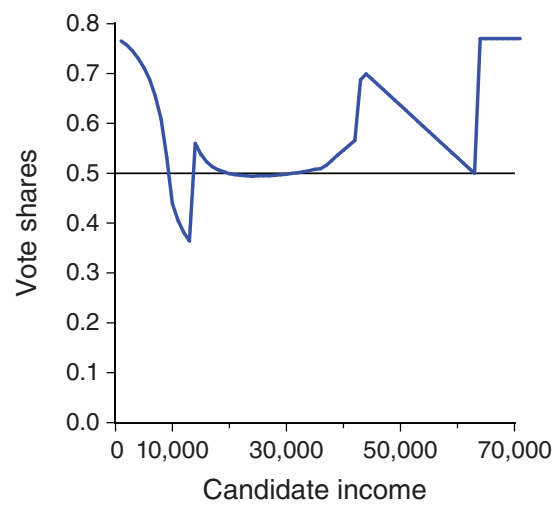

Panel B. Vote for proposals of religious candidates against proposal of $y=\$ 63,000$

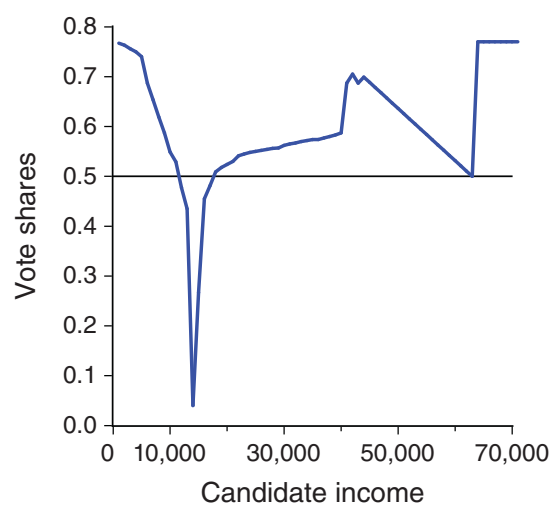

Figure 10. Votes for Proposals of All Candidates against Proposal of $y=\$ 63,000$

households increases, proposals of type $\mathrm{S}$ and type A will continue to be offered (with slight changes in the incomes of the proposers associated with changes in the government budget constraint). The increase in the share of religious types, $\gamma$, increases the vote for A relative to S. A value of $\gamma$ is eventually reached at which the vote for A exceeds 50 percent, defeating S. In Figure 7, this would correspond to the vote at A dipping below the 0.5 line. This occurs when $\gamma \approx 0.17$. But, while A defeats S, A is not an equilibrium; many proposals defeat A. This is illustrated in Figure 10, which shows the vote for all alternative proposals to A when $\gamma=0.17$. Thus, A disrupts equilibrium but itself is not an equilibrium. No Condorcet winner exists among candidates and no political equilibrium arises. In this case, the local winner is defeated by a policy that differs qualitatively, in fact eliminating an active public sector. It bears emphasis that equilibrium fails when enough households have strong preference for private schools, but not enough that a purely private regime $(t=v=g=0)$ is an equilibrium.

It is then natural to ask whether a small set of contenders might defeat all others not in the set, the smallest such set being the "Top Cycle Set." We computed the Top Cycle Set for a fine grid of distinct candidates (equivalent to the Smith Set 1973). Precisely, this is the minimum set of distinct candidates who would each be majority preferred over all candidates not in the set. The set is unique, and is comprised of just the Condorcet winner if one exists. Alternative political processes imply any member of the set might reasonably arise as the policy maker, but only members of this set. For example, if an agenda setter pairs candidates with sequential majority voting, each winner subsequently matched against a non-losing candidate until all candidates are paired, then any but only set members could emerge as the ultimate victor (Miller 1977)..$^{38}$ If this set is small and comprised of candidates with similar policy preferences, then we might

\footnotetext{
${ }^{38}$ This holds with or without forward looking voters, where it is assumed voters must know the agenda and everyone's preferences in the forward-looking case.
} 
investigate the properties of these policies. However, for $\gamma=0.17$, we found that the Top Cycle Set consists of all candidates! The large number of proposals that defeat A, illustrated in Figure 10, gives insight into why the Top Cycle Set is the full set. ${ }^{39}$ We also investigated this set for $\gamma=0.25$ and for $\gamma=0.40$ and found in both cases that the Top Cycle Set is the full set. We interpret this as indicating a highly uncertain outcome. In contrast, we find majority choice equilibrium exists for all values of $\gamma$ ranging from 0 to 1 (in 0.1 increments) when no vouchers are allowed. The extreme uncertainty in the outcome when no majority choice equilibrium exists allowing vouchers suggests households might support a constitutional amendment prohibiting them. This may, in turn, explain why vouchers, including targeted vouchers, have not been more widely adopted.

\section{Conclusion}

We have developed a theoretical model of public choice of a voucher with a quantitative counterpart. Households differ by income and some are strongly religious, with the latter having stronger preference to attend a private (religious) school. Households elect by majority choice a member of the community who sets his preferred policy, consisting of an income tax to finance public expenditure, a per student public schooling expenditure, and perhaps a voucher and income eligibility limit to qualify for the voucher. In any equilibrium that has a community member elected who is a public school patron, a voucher arises that is below public school expenditure and is targeted, i.e., has an income-eligibility limit. A voucher below public school expenditure cross-subsidizes the majority that attend public school, with the eligibility limit reducing public costs by not subsidizing some or all who would opt out of public education with no voucher. The equilibrium has the common qualitative features of empirical educational settings in the United States with vouchers. The model calibrated to the case of the Milwaukee school district can approximate per student public expenditure, the amount of the voucher, the eligibility limit, and the proportion in public school. If a voucher were not allowed, equilibrium public schooling expenditure would be higher. By not allowing a voucher, more relative wealthy students attend public school implying election of a community member who chooses higher public expenditure.

Our model accounts for the widely observed practice of income targeting in US educational voucher programs. Our framework also extends the boundary with respect to modeling in that it endogenizes four key policy variables that characterize such voucher programs: the voucher, the target income level, public school spending, and the tax rate. This requires characterizing the preferred policy of every member of the community. We consider heterogeneity of community members with respect to income differences and a binary religious preference. A challenging but important topic for further study is to expand further the dimensionality of heterogeneity, with respect to educational preferences, including more variation in strength of religious

\footnotetext{
${ }^{39} \mathrm{~A}$ is in the Top Cycle Set and everything that is majority preferred to A, the latter a large set. Then everything that defeats the members of the latter set must be added. And so on. Every preferred policy then ends up in the Top Cycle Set here.
} 
preferences. Another interesting topic for further study would consider majority policy choice in a school district that might attract new residents from and/or drive initial residents to other school districts. Then policy and voting would take account of implied changes in the income distribution and tax base. Key results that permit the characterization of multi-dimensional policies establish that, for those preferring public school, the preferred voucher level, tax rate, and income eligibility limit all follow from tax minimization. These results, embodied Proposition 1, may prove a useful foundation for such further research.

\section{APPENDIX}

\section{PROOF OF PROPOSITION 1:}

a.-We argue that in every case where the superintendent chooses private school for his child, he would as well make choices so that no public sector arises. First, suppose there is a universal voucher. Hence, it is taken up by the superintendent. Choosing $g>v$ to induce any households to choose public school would imply higher taxes, with no offsetting gain to the superintendent. Second, suppose there is no voucher. As in the first case, setting $g>0$ would make the superintendent worse off. Last, suppose there is a targeted voucher. There are two subcases. The first would have $y_{m}$ such that the superintendent gets no voucher himself. Setting $g=v=0$ would minimize taxes to the superintendent, with no offsetting cost to the superintendent. The second subcase has $y_{m}$ such that the superintendent qualifies for the voucher. Suppose that $g>v$. We argue that by lowering $g$ to $v$, the superintendent would be better off. Doing so would lower taxes as: (i) those that continue in public school have lower public cost; and (ii) those that switch to private school with or without a voucher (depending on whether they qualify) imply lower public cost. Thus, lowering $g$ to $v$ would make the superintendent strictly better off. But, then, increasing $y_{m}$ so that anyone who does not qualify for the voucher and attends public school would qualify for the voucher carries no additional cost to the superintendent, but entails a Pareto Improvement (since taking a voucher and attending private school allows supplementation of the voucher). This policy would imply no public sector and would be chosen by the superintendent by our benevolence assumption on breaking policy ties. Using Assumption 2, this completes the proof.

b.-Households that choose public education for given $g$ prefer $\left(t, v, y_{m}\right)$ that solves: $\max _{t, v, y_{m}} U(y(1-t), g)$ subject to $(2 \mathrm{~A})$, which has the same solution as $\min _{t, v, y_{m}} t$ subject to $(2 \mathrm{~A})$, implying the result.

$c(i)$ and $c($ ii) - It is easier to prove part $\mathrm{c}(\mathrm{ii})$ before $\mathrm{c}(\mathrm{i})$. The elected superintendent chooses public school by assumption. Let $g^{*}$ denote his choice of $g$. His preferred $\left(t, v, y_{m}\right)$ must minimize $t$ subject to $(2 \mathrm{~A})$ with $g=g^{*}$ by part b. Write out the Lagrangian function for this problem:

$$
L=t+\lambda\left[v \int_{y_{T}\left(t, v, g^{*}\right)}^{y_{m}} f(y) d y+g^{*} F\left(y_{T}\left(t, v, g^{*}\right)\right)+g^{*} \int_{\min \left[y_{m}, y_{T}\left(t, 0, g^{*}\right)\right]}^{y_{T}\left(t, 0, g^{*}\right)} f(y) d y-t Y\right] .
$$


First, note that since $L_{Y}=-\lambda t, \lambda>0$ by the usual Envelope Theorem argument (keeping in mind the problem is a minimization problem). Now compute the derivative of the Lagrangian with respect to $y_{m}$. We have

$$
L_{y_{m}}=\left\{\begin{array}{ll}
\lambda\left[v f\left(y_{m}\right)-g^{*} f\left(y_{m}\right)\right] & \text { if } y_{m}<y_{T}\left(t, 0, g^{*}\right) \\
\lambda v f\left(y_{m}\right) & \text { if } y_{m}>y_{T}\left(t, 0, g^{*}\right)
\end{array} .\right.
$$

Given a public and private sector and using Assumption 2, i.e., $v \leq g$, implies the Lagrangian is non-increasing if $y_{m}<y_{T}\left(t, 0, g^{*}\right)$ and is increasing if $y_{m}>y_{T}\left(t, 0, g^{*}\right)$. Thus, $y_{m}=y_{T}\left(t, 0, g^{*}\right)$ minimizes $t$. We show next that $v$ is strictly less than $g$, thus implying $y_{m}=y_{T}\left(t, 0, g^{*}\right)$ is the unique minimizer.

We have just shown that if a positive voucher is chosen, then $y_{m}=y_{T}\left(t, 0, g^{*}\right)$ is optimal. The optimal voucher must minimize the Lagrangian in (A1). Substituting for $y_{m}$ and computing the derivative:

$$
L_{v}=\lambda\left[\int_{y_{T}\left(t, v, g^{*}\right)}^{y_{T}\left(t, 0, g^{*}\right)} f(y) d y+\left(g^{*}-v\right) f\left(y_{T}\left(t, v, g^{*}\right)\right) \partial y_{T}\left(t, v, g^{*}\right) / \partial v\right]
$$

Evaluating (A3) at $v=0$, we get: $\left.L_{v}\right|_{v=0}=\lambda g^{*} f\left(y_{T}\left(t, 0, g^{*}\right)\right) \partial y_{T}\left(t, 0, g^{*}\right) / \partial v<0$, since the derivative term is negative. Thus, increasing $v$ above 0 lowers $t$ and is optimal. Using that $y_{T}\left(t, g^{*}, g^{*}\right)=y_{\min }$ (i.e., everyone would use a voucher equal to public expenditure), we have:

$$
\left.L_{v}\right|_{v=g^{*}}=\lambda \int_{y_{\min }}^{y_{T}\left(t, 0, g^{*}\right)} f(y) d y>0 .
$$

The latter implies the optimal $v$ is below $g^{*}$, completing the proof.

$c\left(\right.$ iii).--Refer to Figure 2. From Assumption 1 and that the elected candidate $\left(y^{w}\right)$ chooses public school, a candidate with income marginally higher (lower) than $y^{w}$ would choose a marginally higher (lower) $(t, g)$-pair along $\underline{t}(g)$ if elected. Also, by Assumption 1, among those that choose public school in equilibrium, households with income higher (lower) than $y^{w}$ would then vote for a candidate with marginally higher (lower) income than $y^{w}$. Any households attending a private school and receiving a voucher in equilibrium in $\mathbf{Y}^{+}$prefer electing a household with marginally higher income than $y^{w}$ by definition, while any households receiving a voucher not in $\mathbf{Y}^{+}$prefer a electing a household with marginally lower income than $y^{w}$. All those in equilibrium attending private school with no voucher prefer a candidate that would lower the tax rate, i.e., prefer a household with marginally lower income than $y^{w}$. Thus, absent satisfaction of the balanced voting coalition condition in the Proposition, would imply a marginally higher or lower income candidate would defeat $y^{w}$.

\section{PROOF OF PROPOSITION 2:}

We show first that no other policy choices than the three described in the proposition could be optimal for a household. We have already shown that a household that itself chooses public school chooses a policy with the 
characteristics described in the Proposition. Consider, then, a household choosing its preferred policy that sends their child to private school. If $v=0$, then obviously the household does not itself get a voucher. The household's remaining policy objective is then to minimize the tax rate, which means setting $t=0$. This is policy (i) in Proposition 2. Now consider a household with income $y$ choosing private school and $v>0$. The household will optimally set $y_{m}$ to itself qualify for the voucher. Otherwise, $t=0$ is optimal implying no voucher. We must show that $g=v$ and $y_{m}=\max \left[y, y_{T}(t, 0, g)\right]$. If $v<g$, then lowering $g$ to $v$ relaxes the government budget constraint. This reduction in $g$ can only induce more households to select private schools without any public funding or with less public funding (if they get a voucher) and outlays on any students continuing to attend public school are reduced. Given then $v=g$, if $y \leq y_{T}(t, 0, g)$, setting $y_{m}>y_{T}(t, 0, g)$ unnecessarily increases public expenditure and taxes, while setting any $y_{m} \leq y_{T}(t, 0, g)$ has the same public outlay and thus tax rate. By Assumption 8 , setting $y_{m}=y_{T}(t, 0, g)$ is then optimal. If $y>y_{T}(t, 0, g)$, then setting $y_{m}=y$ maximizes the number of students that choose private school and thus minimizes taxes, while maintaining own eligibility for the voucher. Given these policy characteristics, the household's optimal choice of $v$ maximizes their own utility subject to the relevant equilibrium constraints, as stated in the Proposition.

It remains to be shown that for households that choose private education, if $y>[<] Y / F(y)$, then policy (i) [(ii)] is optimal. To make the argument, restrict choice of $v$ to the vicinity of 0 , this implying a household's optimization problem is: $\max _{t, v \geq 0} U\left(y(1-t)-s^{*}, v+s^{*}\right)$, subject to $t Y=v F(y)$, where $s^{*}$ is the optimal supplement. Keeping in mind the optimum will have $v=g$ (whether $v$ is positive or 0$), y_{T}(t, 0, g) \approx 0$ in the vicinity of $v=0$, implying $y_{m}=y$ and only those with income not exceeding $y$ would consume any public expenditure. (Those with income exceeding $y$ would choose private education without a voucher because public-school expenditure would be approximately 0.) Thus, the relevant government budget constraint is as stated. Substituting in the constraint for $t$, one obtains the first-order condition on $v:-U_{x} \cdot \frac{y}{Y} F(y)+U_{q} \leq 0$, with equality if $v>0$. The condition on $s^{*}$ is $U_{q}=U_{x}$. Using this, the FOC implies $v=(>) 0$ is locally optimal if $y>[<] Y / F(y)$. Local optimality of $v>0$ for $y<Y / F(y)$ implies global optimality. Local optimality of $v=0$ for $y>Y / F(y)$ implies global optimality using the quasi-concavity assumption on the household's optimization problem.

\section{PROOF OF PROPOSITION 3:}

The proof of Propositions $1 \mathrm{c}(\mathrm{ii})$ and $1 \mathrm{c}$ (iii) show that for any $g=g^{*}, t$ is minimized for some $v \in\left(0, g^{*}\right)$. Reinterpret $g^{*}$ as the equilibrium $g$ in the no-voucher equilibrium and apply the same arguments. This implies a lower $t$ exists allowing a targeted voucher than not allowing one. It is immediate that the allocation with the targeted voucher implies a strict Pareto Improvement. It is likewise immediate that the majority preferred targeted voucher is then majority preferred to the no-voucher equilibrium. 
Existence Result with Restricted Electorate.-We develop this result for the simpler case with no religious types. Let $H^{E}$ denote any set of households that: (i) would choose public schooling if the superintendent and thus the policy maker; and (ii) would choose public schooling if any member of the set is the policy maker. The set $H^{E}$ is not unique. Define the electorate to be the set of households that can vote and can stand for election. We have the following result.

PROPOSITION A1: With the electorate restricted to households in any $H^{E}$, a single candidate equilibrium exists with the median-income household in $H^{E}$ elected.

\section{PROOF OF PROPOSITION A1:}

All those that vote choose public school regardless of who from $H^{E}$ is elected and thus have the objective of maximizing $U(y(1-t), g)$. Given the $g$ choice of any household that might be elected, $\left(v, y_{m}\right)$ that minimizes $t$ is preferred by everyone in the electorate. Thus, comparing any two candidates, a voter prefers the candidate whose choice of $g$ maximizes $U(y(1-\underline{t}(g)), g)$. Using Assumption 1, a standard single-crossing argument (see, e.g., Epple and Romer 1991) then implies existence of a Condorcet winner among preferred policies $(g, \underline{t}(g))$ of members of $H^{E}$, with a median-income set member's preferred policy the majority choice. In turn, applying Lemma 2, such an $H^{E}$ member is elected in equilibrium.

\section{REFERENCES}

Bearse, Peter, Gerhard Glomm, and B. Ravikumar. 2000. "On the political economy of means-tested education vouchers.” European Economic Review 44 (4-6): 904-15.

Bearse, Peter, Gerhard Glomm, and B. Ravikumar. 2003. "Majority Voting and Means Tested Vouchers." Unpublished.

Besley, Timothy, and Stephen Coate. 1997. "An Economic Model of Representative Democracy." Quarterly Journal of Economics 112 (1): 85-114.

Black, Duncan. 1948. "On the Rationale of Group Decision Making." Journal of Political Economy $56(1): 23-34$.

Brunner, Eric J., and Stephen L. Ross. 2010. "Is the median voter decisive? Evidence from referenda voting patterns.” Journal of Public Economics 94 (11-12): 898-910.

Chen, Zhiqi, and Edwin G. West. 2000. "Selective versus Universal Vouchers: Modeling Median Voter Preferences in Education." American Economic Review 90 (5): 1520-34.

Epple, Dennis, and Richard E. Romano. 1996a. "Ends against the middle: Determining public service provision when there are private alternatives." Journal of Public Economics 62 (3): 297-325.

Epple, Dennis, and Richard E. Romano. 1996b. "Public Provision of Private Goods." Journal of Political Economy 104 (1): 57-84.

Epple, Dennis, and Richard E. Romano. 1998. "Competition between Private and Public Schools, Vouchers, and Peer Group Effects." American Economic Review 88 (1): 33-62.

Epple, Dennis, and Richard Romano. 2008. "Educational Vouchers and Cream Skimming." International Economic Review 49 (4): 1395-1435.

Epple, Dennis, and Richard E. Romano. 2011. "Peer Effects in Education: A Survey of the Theory and Evidence." In Handbook of Social Economics, Vol. 1b, edited by Jess Benhabib, Alberto Bisin, and Matthew O. Jackson, 1053-1163. Amsterdam: North-Holland.

Epple, Dennis, and Richard Romano. 2014. "On the political economy of educational vouchers." Journal of Public Economics 120: 62-73.

Epple, Dennis, Richard E. Romano, and Miguel Urquiola. 2017. "School Vouchers: A Survey of the Economics Literature.” Journal of Economic Literature 55 (2): 441-92.

Epple, Dennis, and Thomas Romer. 1991. “Mobility and Redistribution.” Journal of Political Economy 99 (4): 828-58. 
Epple, Dennis, and Holger Sieg. 1999. "Estimating Equilibrium Models of Local Jurisdictions." Journal of Political Economy 107 (4): 645-81.

Ewert, Stephanie. 2013. "The Decline in Private School Enrollment." U.S. Census Bureau Social, Economic, and Housing Statistics Division (SEHSD) Working Paper FY12-117.

Glomm, Gerhard, and B. Ravikumar. 1998. "Opting out of publicly provided services: A majority voting result." Social Choice and Welfare 15 (2): 187-99.

Hoyt, William H., and Kangoh Lee. 1998. "Educational vouchers, welfare effects, and voting." Journal of Public Economics 69 (2): 211-28.

Ireland, Norman J. 1990. "The mix of social and private provision of goods and services." Journal of Public Economics 43 (2): 201-19.

Jackson, C. Kirabo, Rucker C. Johnson, and Claudia Persico. 2016. "The Effects of School Spending on Educational and Economic Outcomes: Evidence From School Finance Reforms." Quarterly Journal of Economics 131 (1): 157-218.

Kenny, Lawrence W. 1978. "The collective allocation of commodities in democratic society: A generalization." Public Choice 33 (2): 117-20.

Kenny, Lawrence W. 2005. "The public choice of educational choice." Public Choice 124 (1-2): 205-22.

Miller, Nicholas R. 1997. "Graph-Theoretical Approaches to the Theory of Voting." American Journal of Political Science 21 (4): 769-803.

Nechyba, Thomas J. 1999. "School Financed Induced Migration and Stratification Patterns: The Impact of Private School Vouchers." Journal of Public Economic Theory 1 (1): 5-50.

Nechyba, Thomas J. 2000. "Mobility, Targeting, and Private School Vouchers." American Economic Review 90 (1): 130-46.

Nechyba, Thomas J. 2003. "Centralization, Fiscal Federalism, and Private School Attendance." International Economic Review 44 (1): 179-204.

Osborne, Martin J., and Al Slivinski. 1996. "A Model of Political Competition with Citizen Candidates." Quarterly Journal of Economics 111 (1): 65-96.

Piolatto, Amedeo. 2010. "Education and selective vouchers." Economics of Education Review 29 (6): 993-1004.

Plott, Charles R. 1967. "A Notion of Equilibrium and Its Possibility under Majority Rule." American Economic Review 57 (4): 787-806.

Rangazas, Peter. 1995. "Vouchers and voting: An initial estimate based on the median voter model." Public Choice 82 (3-4): 261-79.

Smith, John H. 1973. "Aggregation of Preferences with Variable Electorates." Econometrica 41 (6): 1027-41.

Stiglitz, J. E. 1974. "The demand for education in public and private school systems." Journal of Public Economics 3 (4): 349-85. 
Copyright of American Economic Journal: Microeconomics is the property of American Economic Association and its content may not be copied or emailed to multiple sites or posted to a listserv without the copyright holder's express written permission. However, users may print, download, or email articles for individual use. 